FEDERAL RESERVE BANK OF SAN FRANCISCO

WORKING PAPER SERIES

\title{
Welfare-based optimal monetary policy with unemployment and sticky prices: A linear-quadratic framework
}

\author{
Federico Ravenna \\ University of California, Santa Cruz \\ Federal Reserve Bank of San Francisco \\ Carl E. Walsh \\ University of California, Santa Cruz \\ Federal Reserve Bank of San Francisco
}

May 2009

Working Paper 2009-15

http://www.frbsf.org/publications/economics/papers/2009/wp09-15bk.pdf

The views in this paper are solely the responsibility of the authors and should not be interpreted as reflecting the views of the Federal Reserve Bank of San Francisco or the Board of Governors of the Federal Reserve System. 


\title{
Welfare-based optimal monetary policy with unemployment and sticky prices: A linear-quadratic framework
}

\author{
Federico Ravenna and Carl E. Walsh*
}

May 2009

\begin{abstract}
In this paper, we derive a linear-quadratic model for monetary policy analysis that is consistent with sticky prices and search and matching frictions in the labor market. We show that the second-order approximation to the welfare of the representative agent depends on inflation and "gaps" that involve current and lagged unemployment. Our approximation makes explicit how the costs of fluctuations are generated by the presence of search frictions. These costs are distinct from the costs associated with relative price dispersion and fluctuations in consumption that appear in standard new Keynesian models. We use the model to analyze optimal monetary policy under commitment and discretion and to show that the structural characteristics of the labor market have important implications for optimal policy.
\end{abstract}

JEL: E52, E58, J64

\section{Introduction}

The canonical new Keynesian model is based on the assumption of monopolistic competition among individual firms together with the imposition of staggered price setting. However, the basic new Keynesian model assumes that there is no unemployment. With sticky prices but flexible wages, the real wage and the marginal rate of substitution between leisure and consumption move together, implying that households are supplying the amount of hours that maximize their utility, given the real wage. Workers are never unemployed and only hours worked per worker vary over the business cycle. As a consequence, the basic new Keynesian model cannot shed light on how unemployment varies over time, how it affects welfare, or whether monetary policy should respond to the unemployment rate.

In contrast to this standard view of labor input, empirical evidence suggests that, at business cycle frequencies, most variation of labor input occurs at the extensive margin. Figure 1 shows HP-filtered log hours per employee and the log number of employees for U.S. total private industries. In periods of below trend output, employed workers work fewer hours, but also fewer

*Department of Economics, University of California, Santa Cruz, CA 95064, and Federal Reserve Bank of San Francisco, 101 Market St, San Francisco, CA 94105. Email: fravenna@ucsc.edu, walshc@ucsc.edu. 
workers are employed. During periods of above trend output, employed workers work longer hours but also more workers are employed. Employment is much more volatile than hours, with the variance of detrended employment almost eight times larger than the variance of hours. These fluctuations in the fraction of workers actually employed reflect fluctuations in unemployment and are quantitatively larger than the fluctuations in hours that standard new Keynesian models treat as the sole of source of labor variation. ${ }^{1}$

In this paper, we show how a new Keynesian model with sticky prices and search-based unemployment can be reduced to a linear Phillips Curve relationship between inflation and unemployment, expected future unemployment, and lagged unemployment. The coefficients in the Phillips curve depend on the underlying structural parameters of the model that govern preferences, the degree of nominal price rigidity, and the search and bargaining processes in the labor market. Our objective is to explore the policy implications of this unemployment-based Phillips Curve.

To carry out this exploration, we derive a second-order approximation to the welfare of the representative household and show how it depends on inflation and the gap between unemployment and the efficient level of unemployment. We show that labor market tightness affects welfare, and all the cost from search inefficiency can be summarized in a single term in the welfare function. In our economy, the first best is attained when both inflation and the unemployment gap are equal to zero. Given the linear representation of the structural equations and a model-consistent quadratic loss function, the model can be used to study monetary policy issues in the same way the standard new Keynesian Phillips Curve has been used. The framework allows for stochastic inefficiencies that distort the flexible-price equilibrium. This introduces a third distortion (the other two being monopolistic competition and sticky prices) that is absent from standard new Keynesian models. ${ }^{2}$

Some of the monetary policy implications of standard new Keynesian models are preserved when search frictions and unemployment are added. For example, productivity shocks do not generate a trade-off between inflation and the unemployment rate gap, but such shocks do require movements in unemployment and real activity. At the same time the volatility of unemployment over the business cycle, beside affecting the goals of the policy maker, changes the monetary transmission mechanism by adding a cost channel for the interest rate along with the traditional demand channel. ${ }^{3}$

A growing number of papers have incorporated the extensive margin and unemployment into new Keynesian models. Examples include Chéron and Langot (1999), Walsh (2003, 2005), Alexopoulos (2004), Christoffel, Kuester, and Linzert (2006), Blanchard and Galí (2006), Krause and Lubik (2007), Barnichon (2006), Thomas (2008), Gertler and Trigari (2006), Gertler, Sala, and Trigari (2007), Krause, Lubik, and Lopéz-Salido (2007), Ravenna and Walsh (2008a, 2008b), Sala, Söderström, and Trigari (2008), and Trigari (2009). The focus of these earlier contributions has extended from exploring the implications for macro dynamics in calibrated models to the estima-

\footnotetext{
${ }^{1}$ This statement applies to new Keynesian models with sticky wages as well as to those with flexible wages. It also applies to most RBC models.

${ }^{2}$ Ravenna and Walsh (2008b) discuss how each of the distortions in models with staggered price setting and labor market frictions affects the trade-offs faced by monetary policy.

${ }^{3}$ While we focus on optimal policy, the implications for simple Taylor rules are also affected by the presence of labor market frictions. For example, the conditions for determinacy do not generally satisfy the so-called Taylor principle. See Kurozumi and Van Zandweghe (2008) for an analysis of determinacy in a sticky price, labor search model that is quite similar in structure to the model we develop here and in Ravenna and Walsh (2008a).
} 
tion of DSGE models with labor market frictions. For example, Sala, Söderström, and Trigari (2008) evaluate monetary policy trade-offs and optimal policy in an estimated model with search and matching frictions in the labor market, but they use an ad hoc quadratic loss function rather than the model consistent welfare approximation we derive.

The papers closest in motivation to ours are Blanchard and Galí (2008) and Thomas (2008). Both these papers make specific assumptions on how the wage setting process generates inefficient fluctuations of the surplus share assigned to each party. Our approach does not take a stand on the sources of these fluctuations, and instead assumes they are exogenous. Thus, no endogenous constraint affects wage adjustment, exactly as in the standard new Keynesian model.

Thomas (2008) incorporates convex costs of posting vacancies and staggered real wage adjustment, and derives a quadratic welfare approximation. Losses are generated by the interaction of nonlinear vacancy posting costs, real wage dispersion and inefficient hiring. The welfare function he derives depends on a term that compounds these different distortions, expressed as a function of log-deviations from the steady state. We maintain the assumption of linear vacancy posting costs, as is more standard in the search and matching literature, and we allow real wages to be flexible. This permits us to obtain a quadratic approximation of the welfare function that is an exact parallel with the basic new Keynesian model without search frictions. We are able, then, to express the welfare function in terms of variables measuring gaps relative to the efficient equilibrium, providing a way to disaggregate the inefficiency created by the search from the standard distortions due to nominal rigidity. We find that this helps to provide new insights into the role of search frictions.

Blanchard and Galí (henceforth BG) also develop a model to explore the implications of labor market frictions for optimal monetary policy in a linear-quadratic framework where the policy maker loss function is derived as an approximation to the households' welfare. BG share with our paper the goal of developing a simple framework akin to the basic new Keynesian model but in which unemployment plays a central role. In contrast to the Mortensen-Pissarides search model we employ, BG assume firms face hiring costs that are increasing in the degree of labor market tightness (measured as new hires relative to unemployment).

There are several significant differences in the specifications of the BG model and ours, and these affect the issues the alternative models are best able to address. BG assume offsetting income and substitution effects on labor supply, implying unemployment remains constant in the face of productivity shocks when prices are flexible. This implies that monetary policy should focus on stabilizing the level of unemployment, as well as inflation. Our model allows unemployment to fluctuate under flexible prices, but because productivity causes the efficient level of unemployment to fluctuate, the appropriate objective of policy is defined in terms of an unemployment rate gap that is more comparable to the output gap that appears in standard new Keynesian models. In addition, the search and matching framework is, in our view, better able to link labor market characteristics to macroeconomic behavior than the hiring costs approach used by BG. For example, the roles of vacancies, job turnover, unemployment benefits, and jobfinding probabilities are explicit in our model, which also generates endogenously a Beveridge curve. The welfare approximation in BG also relies on the assumption that hiring costs are of second order magnitude, an assumption we can dispense with. Finally, BG and Thomas (2008) generate monetary policy trade-offs by assuming real wage rigidity. Instead, we assume stochastic 
fluctuations in worker-firm bargaining shares and flexible real wages. This shock turns out to play the same role as the cost-push shock in the new Keynesian model. This can also be interpreted as deviations of the real wage from its efficient level and so captures some of the same effects generated by assuming real wage rigidity.

In a basic new Keynesian model, cost-push shocks can lead to large losses if the central bank pursues a single-minded focus on price stability. We find, however, that if cost-push shocks are reflective of random deviations of the surplus labor's share from the efficient level, and firms face hiring costs, price stability is nearly optimal.

The rest of the paper is organized as follows. Section 2 presents the basic model, derives a log-linearized version of the model, and discusses the connections between labor market structure and the Phillip curve. The flexible-price, efficient equilibrium is discussed in section 3. The model-consistent welfare approximation and optimal policy are studied in section 4 . The impact of labor market structure on optimal policy is investigated in section 5, while conclusions are summarized in section 6 .

\section{The model economy}

The model consists of households whose utility depends on the consumption of market and home produced goods, wholesale-goods producing firms who employ labor and sell in a competitive goods market, and retail firms who transform the wholesale good into differentiated final goods sold to households in an environment of monopolistic competition. The labor market is characterized by search frictions. Households members are either employed (in a match) or searching for a new match. This means that we do not focus on labor force participation decisions. Retail firms adjust prices according to a standard Calvo specification. The modelling strategy of locating labor market frictions in the wholesale sector where prices are flexible and locating sticky prices in the retail sector among firms who do not employ labor provides a convenient separation of the two frictions in the model. A similar approach was adopted in Walsh (2003, 2005), Ravenna and Walsh (2008a), Thomas (2008), and Trigari (2009).

\subsection{Final goods}

We begin with the description of the final goods market.

\subsubsection{Demand}

The demand for the final goods arises from two sources - households who purchase retail goods to form a consumption bundle and wholesale firms who must employ real resources to recruit and hire workers.

Households Households consist of a large number of members who can be either employed by wholesale firms in production activities or unemployed. In the former case, they receive a market real wage $w_{t}$; in the latter case, they receive a fixed amount $w^{u}$ of household production units. As is standard in the literature on matching frictions, we assume that consumption risks are fully pooled. Households maximize expected discounted utility which depends on total consumption 
of market goods $C_{t}^{m}$ and home production $w^{u}\left(1-N_{t}\right)$ :

$$
C_{t}=C_{t}^{m}+w^{u}\left(1-N_{t}\right)
$$

where $N_{t}$ is the number of household members employed during the period.

Market consumption is an aggregate of goods purchased from the continuum of retail firms which produce differentiated final goods. Preferences over the individual final goods from firm $j$, $C_{t}(j)$, are defined by the standard Dixit-Stiglitz aggregator, so that

$$
C_{t}^{m}(j)=\left[\frac{P_{t}(j)}{P_{t}}\right]^{-\varepsilon} C_{t}^{m}
$$

where

$$
P_{t} \equiv\left[\int_{0}^{1} P_{t}(j)^{1-\epsilon}\right]^{\frac{1}{1-\epsilon}} .
$$

The intertemporal first order condition for the household's decision problem yields the standard Euler equation:

$$
\lambda_{t}=\beta E_{t}\left\{R_{t} \lambda_{t+1}\right\}
$$

where $R_{t}$ is the gross return on an asset paying one unit of consumption aggregate in any state of the world and $\lambda_{t}$ is the marginal utility of consumption. Letting $\hat{x}_{t}$ denote the log deviation of a variable $x$ around its steady-state value, we obtain the standard first-order approximation to the Euler condition implied by intertemporal optimization on the part of the representative household:

$$
\hat{c}_{t}=E_{t} \hat{c}_{t+1}-\left(\frac{1}{\sigma}\right)\left(i_{t}-E_{t} \pi_{t+1}\right) .
$$

Wholesale firms Final goods are also purchased by wholesale firms. We assume these firms must pay a cost $P_{t} \kappa$ for each job they post. Since job postings are homogenous with final goods, wholesale firms solve a static problem symmetric to the household's one: they buy individual final goods $v_{t}(j)$ from each $j$ final-goods-producing retail firm so as to minimize total expenditure, given that the production function of a unit of final good aggregate $v_{t}$ is given by

$$
\left[\int_{0}^{1} v_{t}(j)^{\frac{\varepsilon-1}{\varepsilon}} d z\right]^{\frac{\varepsilon}{\varepsilon-1}} \geq v_{t}
$$

The demand by wholesale firms for the final goods produced by retail firm $j$ are given by

$$
v_{t}(j)=\left[\frac{P_{t}(j)}{P_{t}}\right]^{-\varepsilon} v_{t}
$$

Total expenditure on final goods by households and wholesale firms is 


$$
\begin{aligned}
E_{t} & =\int_{0}^{1} P_{t}(j) C_{t}^{m}(j) d j+\kappa \int_{0}^{1} P_{t}(j) v_{t}(j) d j \\
& =\int_{0}^{1} P_{t}(j)\left[C_{t}^{m}(j)+\kappa v_{t}(j)\right] d j \\
& =P_{t}\left(C_{t}^{m}+\kappa v_{t}\right)
\end{aligned}
$$

where $Y_{t}^{d}(j) \equiv C_{t}^{m}(j)+\kappa v_{t}(j)$ is total demand for final good $j$.

\subsubsection{Supply}

Each retail firm purchases wholesale output at price $P_{t}^{w}$ in a competitive market. The wholesale good is then converted into a differentiated final good sold to households and wholesale firms. Retail firms maximize profits subject to a CRS technology for converting wholesale goods into final goods, the demand functions (1) and (3a), and a restriction on the frequency with which they can adjust their price.

Retail firms adjust prices according to the Calvo updating model. Each period a firm can adjust its price with probability $1-\omega$. Retail firms' only input into production is the wholesale goods, so each retail firm's nominal marginal cost is $P_{t}^{w}$ and all firms that adjust their price set the same price. The real marginal cost for retail firms is the price of the wholesale good relative to the price of final output, $P_{t}^{w} / P_{t}$. This is just the inverse of the markup of retail over wholesale

goods. The markup will depend on the labor market frictions that characterize the wholesale sector.

A retail firm that can adjust its price in period $t$ chooses $P_{t}(j)$ to maximize

$$
\sum_{i=0}^{\infty}(\omega \beta)^{i} E_{t}\left[\left(\frac{\lambda_{t+i}}{\lambda_{t}}\right)\left(\frac{P_{t}(j)-P_{t+i}^{w}}{P_{t+i}}\right) Y_{t+i}(j)\right]
$$

subject to

$$
Y_{t+i}(j)=Y_{t+i}^{d}(j)=\left[\frac{P_{t}(j)}{P_{t+i}}\right]^{-\varepsilon} Y_{t+i}^{d}
$$

where $Y_{t}^{d}$ is aggregate demand for the final goods basket. The standard pricing equation obtains which, when linearized around a zero-inflation steady state yields the standard new Keynesian Phillips curve:

$$
\pi_{t}=\beta E_{t} \pi_{t+1}-\delta \hat{\mu}_{t}
$$

where $\delta=(1-\omega)(1-\omega \beta) / \omega$, and

$$
\mu_{t} \equiv \frac{P_{t}}{P_{t}^{w}}
$$

is the retail price markup.

\subsubsection{Market clearing}

Equations (2) and (5) are standard. The key difference between a model with labor market frictions and a standard new Keynesian model is in the factors that affect real marginal cost. A second, less fundamental difference arises, as we discuss in section 2.2 , because the real costs 
associated with posting job vacancies generates a wedge between consumption and output. Thus, one cannot simply replace $\hat{c}_{t}$ in (2) with an output measure. Instead, goods market clearing requires that household consumption of market produced goods equals the output of the retail sector minus final goods purchased by wholesale firms to cover the costs of posting job vacancies (see section 2.2). Hence, goods market equilibrium takes the form

$$
Y_{t}=C_{t}^{m}+\kappa V_{t}=C_{t}-w^{u}\left(1-N_{t}\right)+\kappa V_{t}
$$

where $V_{t}$ is the aggregate number of vacancies posted and $\kappa$ is the cost per vacancy. When linearized, this condition becomes

$$
\hat{y}_{t}=\left(\frac{C}{Y}\right) \hat{c}_{t}+w^{u} \hat{n}_{t}+\left(\frac{\kappa V}{Y}\right) \hat{v}_{t}
$$

The constant returns to scale technology for retail good's production implies, when linearized, that $\hat{y}_{t}=\hat{n}_{t}+z_{t}$ where $\hat{n}$ is employment and $\hat{z}$ is an aggregate productivity disturbance. Thus, (6) can be expressed as

$$
\hat{c}_{t}=\left(\frac{Y}{C}\right)\left(1-w^{u}\right) \hat{n}_{t}+\left(\frac{Y}{C}\right) z_{t}-\left(\frac{\kappa V}{C}\right) \hat{v}_{t}
$$

\subsection{Wholesale goods, employment and wages}

The labor market is characterized by search frictions. Each period begins with $N_{t-1}$ existing matches. There is an exogenous probability $\rho$ that a match breaks up prior to producing output. Those workers not in a match at the start of the period or who do not survive the exogenous separation hazard seek new matches. Thus, the number of job seekers is

$$
u_{t} \equiv 1-(1-\rho) N_{t-1}
$$

Unemployed workers are matched stochastically with job vacancies. The matching process is represented by a CRS matching function

$$
m_{t}=\chi v_{t}^{\alpha} u_{t}^{1-\alpha}
$$

where $u_{t}$ is the number of job seekers, $v_{t}$ is the number of posted job openings and $0<\alpha<1$. $^{4}$ Letting $\theta_{t} \equiv v_{t} / u_{t}$ measure of labor market tightness, $m_{t}=\chi \theta_{t}^{\alpha} u_{t}$. The number of matches that produce in period $t$ is

$$
N_{t}=(1-\rho) N_{t-1}+m\left(u_{t}, v_{t}\right)
$$

The linear approximations for the relationship between job seekers and matches and for the evolution of employment are

$$
\hat{u}_{t}=-(1-\rho)\left(\frac{\bar{N}}{\bar{u}}\right) \hat{n}_{t-1} \equiv-\eta \hat{n}_{t-1} .
$$

\footnotetext{
${ }^{4}$ We take the number of job seekers as our measure of unemployment and will so refer to $u_{t}$. The standard measure of unemployment would more closely match the number of workers not in a match at the end of the period, $1-N_{t}$. The two are related since $u_{t+1}=1-N_{t}+\rho N_{t}$.
} 
and

$$
\hat{n}_{t}=(1-\rho) \hat{n}_{t-1}+\rho\left(\alpha \hat{\theta}_{t}+\hat{u}_{t}\right)
$$

where $\bar{X}$ denotes the steady-state value of $X_{t}$. Note that $\hat{u}_{t}$ is predetermined at time $t$. Combining (9) and (10),

$$
\hat{n}_{t}=(1-\rho-\rho \eta) \hat{n}_{t-1}+\alpha \rho \hat{\theta}_{t}=\rho_{u} \hat{n}_{t-1}+\alpha \rho \hat{\theta}_{t},
$$

where $\rho_{u} \equiv 1-\rho-\rho \eta=(1-\rho)(1-\rho \bar{N} / \bar{u})$.

To hire workers, wholesale firms must post vacancies. Given free entry, the value of a vacancy is zero in equilibrium. This so-called job posting condition implies that the expected value of a filled job will equal the cost of posting a vacancy, or

$$
q_{t} J_{t}=\kappa,
$$

where $J_{t}$ is the value of a filled job, $q_{t}$ is the probability a firm with a vacancy will fill it, and $\kappa$ is the cost of posting a vacancy. The value of a filled job is also equal to the firm's current period profit plus the discounted value of having a match in the following period. If a job produces output $Z_{t}$ and $w_{t}$ is the wage paid to the worker, than the value of a filled job in terms of final goods is

$$
J_{t}=\left(\frac{P_{t}^{w}}{P_{t}}\right) Z_{t}-w_{t}+(1-\rho) \beta E_{t}\left(\frac{\lambda_{t+1}}{\lambda_{t}}\right) J_{t+1}
$$

or

$$
\frac{Z_{t}}{\mu_{t}}=w_{t}+\frac{\kappa}{q_{t}}-(1-\rho) \beta E_{t}\left(\frac{\lambda_{t+1}}{\lambda_{t}}\right)\left(\frac{\kappa}{q_{t+1}}\right)
$$

where $\beta\left(\frac{\lambda_{t+1}}{\lambda_{t}}\right) \equiv R_{t}^{-1}$ is the stochastic discount factor. The left side of (12) is the marginal product of a worker. The right side is the marginal cost of a worker to the firm. In the absence of labor market frictions, this cost would just be the real wage, and one would have $Z_{t} / \mu_{t}=w_{t}$, or $1 / \mu_{t}=w_{t} / Z_{t}$; this corresponds to the standard new Keynesian model, where the real marginal cost variable that drives inflation is the real wage divided by labor productivity. With labor market frictions, additional factors come into play. According to (12), the cost of labor also includes the search costs associated with hiring $\left(\kappa / q_{t}\right)$ and the discounted recruitment cost savings if an existing employment match survives into the following period.

The real wage appears in (12). Two approaches have been taken in the literature to determine the wage. A standard approach allowing for flexible wages is to assume Nash bargaining between the firm and the worker. If the bargaining weights are fixed, each participant in the bargain will receive a fixed share of the total surplus. Shimer (2005) pointed out that the real wage responds strongly to productivity shocks, leaving unemployment much less volatile than in the data. In light of the "Shimer puzzle," many authors have introduced some form of real wage rigidity (see for example Hall, 2005, Gertler and Trigari, 2007). Since our objective is to develop a simple framework that parallels the basic new Keynesian model yet incorporates unemployment, we will follow the literature that assumes Nash bargaining over wages. This choice is consistent with the assumption of flexible wages underlying the basic new Keynesian model and allows a straightforward comparison of the policy implications of the two frameworks. We deviate from the standard assumption of fixed bargaining weights, however, by allowing the division of a match 
surplus to vary stochastically.

Let $b_{t}$ denote the worker's share of the job surplus in period $t$. Then the equilibrium real wage is

$$
w_{t}=\left(1-b_{t}\right) w^{u}+b_{t}\left[\frac{Z_{t}}{\mu_{t}}+(1-\rho)\left(\frac{1}{R_{t}}\right) E_{t}\left(\frac{\kappa}{q_{t+1}}\right) p_{t+1}\right],
$$

where $p$ is the job-finding probability of an unemployed worker. Substituting (13) into (12), one finds that the relative price of wholesale goods in terms of retail goods is equal to

$$
\frac{P_{t}^{w}}{P_{t}}=\frac{1}{\mu_{t}}=\frac{\tau_{t}}{Z_{t}}
$$

where

$$
\tau_{t} \equiv w^{u}+\left(\frac{1}{1-b_{t}}\right)\left\{\frac{\kappa}{q_{t}}-(1-\rho)\left(\frac{1}{R_{t}}\right) E_{t}\left(1-b_{t} p_{t+1}\right) \frac{\kappa}{q_{t+1}}\right\}
$$

Given the matching function and noting that $q_{t}=m_{t} / v_{t}=\chi \theta_{t}^{\alpha-1}$ and $p_{t}=m_{t} / u_{t}=\chi \theta_{t}^{\alpha}=$ $\theta_{t} q_{t},(14)$ and (15) can be linearized around the steady state to express the retail price markup in terms of labor market tightness as

$$
\hat{\mu}_{t}=z_{t}-\hat{\tau}_{t}=z_{t}-\mu\left(a_{1} \hat{\theta}_{t}-\beta a_{2} E_{t} \hat{\theta}_{t+1}-\beta a_{3} \hat{r}_{t}+B \hat{b}_{t}\right)
$$

where

$$
\begin{gathered}
\hat{\theta}_{t}=\hat{v}_{t}-\hat{u}_{t} . \\
a_{1}=\left(\frac{1-\alpha}{1-b}\right)\left(\frac{\kappa \bar{V}}{\rho \bar{N}}\right) \\
a_{2}=\left(\frac{1-\rho}{1-b}\right)\left[1-\alpha-b\left(\frac{\rho \bar{N}}{\bar{u}}\right)\right]\left(\frac{\kappa \bar{V}}{\rho \bar{N}}\right) \\
a_{3}=\left(\frac{1-\rho}{1-b}\right)\left[1-b\left(\frac{\rho \bar{N}}{\bar{u}}\right)\right]\left(\frac{\kappa \bar{V}}{\rho \bar{N}}\right) \\
B=\frac{b}{1-b}\left[1-\mu w^{u}+\mu \beta(1-\rho)\left(\frac{\kappa \bar{V}}{\bar{u}}\right)\right] .
\end{gathered}
$$

The linearized expressions for inflation and the markup illustrate how labor market tightness affects inflation. A rise in labor market tightness reduces the retail price markup, increasing the marginal cost of the retail firms. This leads to a rise in inflation. Expected future labor market tightness also affects current inflation. For a given $\hat{\theta}_{t}$, a rise in $E_{t} \hat{\theta}_{t+1}$ increases the markup and reduces current inflation. ${ }^{5}$ It does so through its effects on current wages. Expectations of labor market tightness increase the incentive of firms to post vacancies. This would normally lead to a rise in current tightness. However, since the coefficient on $E_{t} \hat{\theta}_{t+1}$ measures the impact on $\mu_{t}$ when $\hat{\theta}_{t}$ remains constant, wages must fall to offset the rise in vacancies that would otherwise occur and keep $\hat{\theta}_{t}$ constant. Finally, there is a cost channel effect in that the real interest rate has a direct impact on $\mu_{t}$ and therefore on inflation. ${ }^{6}$ This arises since it is the present discounted value of expected future labor market conditions that affects the firm's decision to post an extra vacancy.

\footnotetext{
${ }^{5}$ In our baseline calibration discussed below, $a_{2}<0$.

${ }^{6}$ The cost channel in our model depends on the real rate of interest. In standard analyses of the cost channel, it is the nominal rate of interest that affects real marginal cost. See Ravenna and Walsh (2006).
} 


\subsection{The linear approximation}

The linearized model is given by (2), (5), (7), (9), (10), (17) and (16). These equations jointly determine $\hat{c}_{t}, \pi_{t}, \hat{n}_{t}, \hat{u}_{t}, \hat{v}_{t}, \hat{\mu}_{t}, \hat{\theta}_{t}$, and $i_{t}$ once a specification of policy is added to determine the nominal rate of interest $i_{t}$. An appendix, available from the authors, shows how these seven equations can be reduced to a system of two equilibrium conditions that correspond to the new Keynesian expectational IS curve and Phillips curves but expressed in terms of unemployment and inflation rather than in terms of an output gap and inflation. These two relationships are

$$
\hat{u}_{t+1}=\gamma E_{t} \hat{u}_{t+2}+(1-\gamma) \hat{u}_{t}-\left[\frac{1}{\sigma\left(\varphi_{1}+\varphi_{2}\right)}\right] r_{t}-\left(\frac{1}{\varphi_{1}+\varphi_{2}}\right)\left(\frac{Y}{C}\right)\left(1-\rho_{z}\right) z_{t}
$$

and

$$
\begin{aligned}
\pi_{t}= & \beta E_{t} \pi_{t+1}+\left(\frac{\delta \mu}{\alpha \rho \eta}\right)\left[a_{2} \beta\left(E_{t} \hat{u}_{t+2}-\rho_{u} \hat{u}_{t+1}\right)-a_{1}\left(\hat{u}_{t+1}-\rho_{u} \hat{u}_{t}\right)\right] \\
& +\beta \delta \mu a_{3} r_{t}+\delta B \hat{b}_{t}-\delta z_{t}
\end{aligned}
$$

where

$$
\begin{gathered}
\gamma \equiv\left(\frac{\varphi_{1}}{\varphi_{1}+\varphi_{2}}\right), \\
\varphi_{1} \equiv-\left(\frac{Y}{\eta C}\right)\left[1-w^{u}-\left(\frac{\kappa \bar{V}}{\alpha \rho \bar{Y}}\right)\right] \text {, and } \varphi_{2} \equiv\left(\frac{\kappa \bar{V}}{\alpha \rho \eta \bar{C}}\right)\left(\alpha \rho \eta+\rho_{u}\right) .
\end{gathered}
$$

In a standard new Keynesian model, the Euler condition is forward looking, containing no lagged endogenous variables. It has become standard to assume habit persistence on the part of households so that lagged output appears in the Euler condition. In our model, $\hat{u}_{t}$, which is predetermined at time $t$, appears because the real search costs associated with vacancies, and therefore equilibrium production, are affected by the number of job seekers, consisting of workers who enter the period without matches or are displaced from existing matches. This leads to the presence of a backward-looking component in the IS relationship without the introduction of habit persistence. As shown below, in section 3, when the steady-state equilibrium is efficient, the weights on $E_{t} \hat{u}_{t+2}$ and $\hat{u}_{t}$ in (18) are each approximately one-half. ${ }^{7}$

Equation (19) is the new Keynesian Phillips curve in the presence of labor market search frictions. An increase in unemployment (job seekers) lowers real marginal cost and reduces inflation. Just as greater labor market tightness in the future reduced the current cost of labor, a fall in future unemployment (an increase in labor market tightness) will lower current inflation through its effect on current real marginal cost.

As is well understood, in a standard new Keynesian model, the absence of explicit interest rate objectives in the loss function means that the IS relationship does not impose any constraints on the central bank. Thus, optimal policy is only constrained by the Phillips curve. In the search friction new Keynesian model the optimal policy problem cannot be equally simplified, since the real interest rate appears directly in the Phillips curve. However, a form that even more closely parallels the standard new Keynesian Phillips curve can be obtained by using (18) to eliminate the real interest rate from (19). Making this substitution would expresses inflation as a function

\footnotetext{
${ }^{7}$ The weights are $\beta /(1+\beta)$ and $1 /(1+\beta)$ respectively.
} 
of expected future inflation and expected future, current, and lagged unemployment rates:

$$
\begin{aligned}
\pi_{t}= & \beta E_{t} \pi_{t+1}+\beta \delta \mu\left(\frac{a_{2}}{\alpha \rho \eta}+\frac{a_{3} \sigma \gamma}{1-\gamma}\right) E_{t} \hat{u}_{t+2}-\delta \mu\left(\frac{a_{1}+\beta a_{2} \rho_{u}}{\alpha \rho \eta}+\frac{\beta a_{3} \sigma}{1-\gamma}\right) \hat{u}_{t+1} \\
& +\delta \mu\left(\frac{a_{1} \rho_{u}}{\alpha \rho \eta}+\beta a_{3} \sigma\right) \hat{u}_{t-1}+\delta B \hat{b}_{t}-\delta\left[1+\beta \mu a_{3} \sigma\left(\frac{\bar{Y}}{\bar{C}}\right)\left(1-\rho_{z}\right)\right] z_{t} .
\end{aligned}
$$

\section{The efficient equilibrium}

Equations (14) and (15) imply that the job posting condition takes the form

$$
\frac{Z_{t}}{\mu_{t}}=w^{u}+\left(\frac{1}{1-b_{t}}\right)\left\{\frac{\kappa}{q_{t}}-\beta(1-\rho) E_{t}\left(\frac{\lambda_{t+1}}{\lambda_{t}}\right)\left(1-b_{t} p_{t+1}\right) \frac{\kappa}{q_{t+1}}\right\} .
$$

When prices are flexible, $\mu_{t}=\mu>1$ for all $t$. However, a tax-subsidy policy that offsets the allocative effects of the steady-state markup is not sufficient to ensure that the resulting flex-price equilibrium is efficient as is the case in the standard new Keynesian model. Inefficient job posting can lead to an inefficient level of vacancies and unemployment. Efficiency requires $\mu_{t}=\mu=1$ and $b_{t}=1-\alpha$. This second condition is the familiar the Hosios condition for efficient vacancy creation. ${ }^{8}$ Letting a superscript $e$ denote the efficient equilibrium, the job posting condition takes the form

$$
Z_{t}=w^{u}+\left(\frac{1}{\alpha}\right)\left\{\frac{\kappa}{\varphi}\left(\theta_{t}^{e}\right)^{1-\alpha}-\beta(1-\rho) E_{t}\left(\frac{\lambda_{t+1}^{e}}{\lambda_{t}^{e}}\right) \kappa\left[\frac{\left(\theta_{t+1}^{e}\right)^{1-\alpha}}{\varphi}-(1-\alpha) \theta_{t+1}^{e}\right]\right\} .
$$

When linearized,and expressed in terms of the efficient level of unemployment, this yields

$$
a_{1}\left(\hat{u}_{t+1}^{e}-\rho_{u} \hat{u}_{t}^{e}\right)-\beta a_{2}\left(E_{t} \hat{u}_{t+2}^{e}-\rho_{u} \hat{u}_{t+1}^{e}\right)-\beta a_{3} \alpha \rho \eta \hat{r}_{t}^{e}=-\alpha \rho \eta \hat{z}_{t}
$$

where $r_{t}^{e}$ is the equilibrium real interest rate in the efficient equilibrium.

In addition, the IS relationship (18) in the efficient equilibrium takes the form

$$
\begin{aligned}
\hat{u}_{t+1}^{e}= & \left(\frac{\beta}{1+\beta}\right) E_{t} \hat{u}_{t+2}^{e}+\left(\frac{1}{1+\beta}\right) \hat{u}_{t}^{e} \\
& -\left(\frac{1}{\sigma}\right)\left(\frac{1}{1+\beta}\right)\left(\frac{\eta \bar{C}}{\delta_{2} \bar{Y}}\right) r_{t}^{e}-\left(\frac{1}{1+\beta}\right)\left(\frac{\bar{Y}}{\bar{C}}\right)\left(1-\rho_{z}\right) \hat{z}_{t} .
\end{aligned}
$$

where $\delta_{2}=(1-\rho)(\kappa \bar{V} / \alpha \bar{U})(\alpha-1+\bar{U} / \rho \bar{N})$.. The responses of the efficient unemployment rate $\hat{u}_{t+1}^{e}$ and the real interest rate in the face of productivity shocks can be found by jointly solving (21) and (22)..$^{9}$

To investigate how $\hat{u}^{e}$ moves in response to a productivity shock, we employ a calibrated

\footnotetext{
${ }^{8}$ The Hosios condition requres that labor's share of the surplus, $b$, equal the elasticity of matches with respect to unemployment, $1-\alpha$.

${ }^{9}$ In (22), we have followed Neiss and Nelson (2003) in defining $\hat{u}_{t+1}^{e}$ relative to last-period's efficient unemployment rate. Thus, the path of $\hat{u}_{t+i}^{e}$ is that for an economy that has always been in an efficient equilibrium. Alternatively, Woodford (2003) defines the flex-price and efficient equilibria conditional on the actual outcomes in the previous period. In that case, $\hat{u}_{t+1}^{e}$ would depend on $\hat{u}_{t}$. Edge (2003) discusses these two alternative definitions in the context of a model in which the lagged capital stock is an endogenous state variable. We follow the Neiss-Nelson definition; as Edge shows, it proves more convenient for deriving the welfare approximation we use to characterize optimal monetary policy.
} 
version of the model. We parameterize the model to standard values in the literature. The baseline values for the model parameters are given in Table 1. We impose the Hosios condition by setting $b=1-\alpha$. By calibrating the steady-state job finding probability $q$ and the replacement ratio $\phi \equiv w^{u} / w$ directly, we use steady-state conditions to solve for the job posting cost $\kappa$ and the wage $w \cdot{ }^{10}$ Given the parameters in Table 1, the remaining parameters and the steady-state values needed to obtain the log-linear approximation can be calculated.

Equations (21) and (22) imply that the equilibrium unemployment responds to productivity shocks even under flexible prices. Figure 2 illustrates the impulse response of the efficient level of unemployment and labor market tightness to a one-unit productivity innovation. The solid lines shows the response when the shock is serially uncorrelated, while the dashed lines are constructed for $\rho_{z}=0.8$. Since our calibration imposes the Hosios condition, $\hat{u}^{e}$ corresponds to the efficient deviation of unemployment from its steady-state value. As the figure shows, positive productivity lowers unemployment. It also causes a jump in vacancies that significantly increases labor market tightness. The rise in vacancies leads to a drop in the unemployment rate over time. Since the productivity increase is temporary, unemployment returns to its initial level. When $\rho_{z}=0$, labor market tightness returns almost immediately to its steady-state value.

Even when the underlying shock is serially uncorrelated, however, unemployment takes about a year to return to its steady-state value. As expected, the response of flexible-price unemployment is both larger and more persistent when the productivity shock is highly serially correlated.

The dependence of $u^{e}$ on productivity contrasts with the implications of the BG model, which is set up so that the natural rate of unemployment is constant. A key challenge faced by central banks is distinguishing between efficient and inefficient movements in unemployment in response to exogenous shocks. While we maintain the standard assumption that the state variables are known to the policy maker, we see as an advantage of our framework is its explicit incorporation of time-variation in the efficient rate of unemployment.

\section{Optimal monetary policy}

To study optimal monetary policy, we assume the monetary authority's objective is to maximize the expected present discounted value of the utility of the representative household. A rich and insightful literature has developed from the initial contributions of Rotemberg and Woodford (1996) and Woodford (2003) employing policy objectives based on a second order approximation to the welfare of the representative agent. As is well known, the appropriate welfare approximation depends on the exact structure of the model. In this section, we discuss the quadratic objective function that arises in our model with sticky prices and labor market frictions.

While we focus on optimal policies, it is worth noting that, as Kurozumi and Van Zandwedge (2008) demonstrate, the conditions that simple policy rules must satisfy to ensure determinacy and E-stability in a labor search model can be quite different from the standard Taylor principle.

\footnotetext{
${ }^{10}$ To find $\kappa$ and $w$, assume $w^{u}=\phi w$, where $\phi$ is the wage replacement rate. Then (12) and (13) can be written as$$
\frac{1}{\mu}=w+\frac{\kappa}{\bar{q}}[1-\beta(1-\rho)]
$$$$
[1-\phi(1-b)] w=b\left[\frac{1}{\mu}+(1-\rho) \beta \kappa \theta\right]
$$

and these two equations can be jointly solved for $\kappa$ and $w$. The value of $w^{u}$ is then given by $\phi w$.
} 
Using a model very similar to the one we employ in this paper and in Ravenna and Walsh (2008a), Kurozumi and Van Zandwedge show that the role of the real interest rate in affecting vacancy creation plays a critical role in affecting determinacy. A rise in the real interest rate in response to a rise in expected future inflation lowers current vacancy creation, but it also generates expectations of a tighter labor market in the future when demand recovers. This vacancy channel of a higher real interest rate creates expectations of higher future inflation and so the initial rise in expected inflation can be self-fulfilling. ${ }^{11}$

\subsection{The quadratic approximation to welfare}

In analyzing optimal policy, it will be useful to introduce some "gap" variables - variable expressed relative to their stochastic, efficient equilibrium counterparts. Let $\tilde{x}_{t} \equiv \hat{x}_{t}-\hat{x}_{t}^{e}$. Expressed in terms of gaps, the second order approximation to welfare is

$$
\sum_{i=0}^{\infty} \beta^{i} U\left(C_{t+i}\right)=\frac{U(\bar{C})}{1-\beta}-\frac{\varepsilon}{2 \delta} U_{c} \bar{C} \sum_{i=0}^{\infty} \beta^{i} L_{t+i}+\text { t.i.p. }
$$

where t.i.p. denotes terms independent of policy, the period-loss function is

$$
L_{t}=\pi_{t}^{2}+\lambda_{0} \tilde{c}_{t}^{2}+\lambda_{1} \tilde{\theta}_{t}^{2},
$$

where $\lambda_{0}=\sigma(\delta / \varepsilon)$ and $\lambda_{1}=(1-\alpha)(\delta / \varepsilon)(\kappa \bar{V} / \bar{C})$. Details are given in an appendix available from the authors. It is important to note that the weight on $\tilde{c}_{t}^{2}$ is the same as obtained in a standard new Keynesian model once it is recognized that our implicit elasticity of hours with respect to the wage is zero. ${ }^{12}$

To understand this loss function, recall that the utility of the household depends on total consumption of market produced goods and home produced consumption. In a standard new Keynesian model, utility also depends on the disutility of labor, but with constant returns to scale, labor is proportional to wholesale output which in turn is equal to consumption, up to first order. Utility is reduced by inefficient volatility of consumption, yet inflation also reduces utility because it leads to an inefficient composition of consumption for a given level of wholesale output, due to the dispersion of relative prices inflation generates. That is, even if total consumption is equal to the efficient level, up to first order, the composition of consumption across individual goods is inefficient in the presence of inflation.

In our model, this distortion arising from inflation is also present. Therefore, as in the new Keynesian model welfare is decreasing in inflation volatility: staggered price adjustment means that inflation causes inefficient dispersion of relative prices across the retail firms. However, in the present model, total consumption is the sum of market produced consumption and home produced consumption. Even if inflation is zero, so that market consumption is obtained through an efficient combination of the differentiated market goods, the composition of total consumption between market goods and home production can be inefficient if labor market tightness differs

\footnotetext{
${ }^{11}$ Llosa and Tuesta (2006) find the presence of a cost channel of the type analyzed in Ravenna and Walsh (2006) also has a significant effect on the conditions for determinacy.

${ }^{12}$ In a basic new Keynesian model, the relative weight on the output gap in the loss function is, in terms of the present notation, $\delta(\sigma+\eta) /(1+\eta \varepsilon) \varepsilon$, where $\eta$ is the inverse of the wage-elasticity of labor supply (see Woodford 2003 or Walsh 2003, p. 555). If $\eta=0$, one obtains $\sigma \delta / \varepsilon$, which is the value of $\lambda_{0}$ in (23).
} 
from it efficient value. Hence, even if inflation and the consumption gaps are zero, the household is inefficiently combining home and market consumption whenever the tightness gap is nonzero. This implies welfare depends on the volatility of labor market tightness, represented by the term $\lambda_{1} \tilde{\theta}_{t}^{2}$. Any deviation of labor market tightness from its efficient level causes welfare losses.

This result does not hinge on our particular specification of home production, but simply on the fact that an alternative way of generating utility is available to unemployed agents, and this alternative does not suffer from the search friction necessary to produce matches and market consumption. In our setup, this activity implies that a portion of total consumption can be obtained without the use of the search technology; the result would carry through in a setup where unemployed workers consume only market-produced goods but also generate utility from leisure hours.

The intuition can be explained as follows. In a standard new Keynesian model with Walrasian labor markets we can write the instantaneous utility $\mathbf{U}_{t}$ in terms of a single variable, for example $N_{t}$, using the standard market clearing conditions:

$$
\begin{aligned}
\mathbf{U}_{t} & =\mathbf{U}\left(C_{t}, N_{t}\right) \\
& =\mathbf{U}\left(\Delta_{t}^{-1} A_{t} N_{t}, N_{t}\right)
\end{aligned}
$$

where we used the relationship $C_{t}=Y_{t}=\Delta_{t}^{-1} Y_{t}^{w}=\Delta_{t}^{-1} A_{t} N_{t}$ and $\Delta_{t}=\int_{0}^{1}\left[\frac{P_{t}(z)}{P_{t}}\right]^{-\varepsilon} d z$. In the Taylor expansion of the utility function, volatility in the price dispersion term $\Delta_{t}^{-1}$ leads to a quadratic term in inflation in $L_{t}$. It describes the wedge between fluctuations in $Y_{t}^{w}$ and fluctuations in $C_{t}$. With a separable utility function, the wholesale output term, $A_{t} N_{t}$, is equal to consumption up to first order, and the disutility of the output and labor term are proportional in the Taylor expansion, and can be summed together. These terms, in deviation from their efficient level, result in the quadratic output gap term in the period loss function. It would be possible in the standard new Keynesian model to rewrite the quadratic approximation to the utility function in terms of a quadratic inflation term, consumption gap term, and a labor (hours) gap term.

However, the labor market term in (23) does not correspond to the labor gap term in a standard new Keynesian model. Instead, it arises because of the existence of search frictions. In our setup, we can write

$$
\begin{aligned}
\mathbf{U}_{t} & =\mathbf{U}\left(C_{t}\right) \\
& =\mathbf{U}\left(C_{t}^{m},\left(1-N_{t}\right) w^{u}\right) \\
& =\mathbf{U}\left(\Delta_{t}^{-1} A_{t} N_{t}-\kappa v_{t},\left(1-N_{t}\right) w^{u}\right)
\end{aligned}
$$

where we have used the relationship $Y_{t}=\Delta_{t}^{-1} Y_{t}^{w}=\Delta_{t}^{-1} A_{t} N_{t}=C_{t}^{m}+\kappa v_{t}$. In the standard new Keynesian model, the Taylor expansion has a term in $N_{t}$ because the loss of utility from getting an extra unit of $C_{t}$ is nonlinear in $N_{t}$. Our model assumes that the loss from getting an extra unit of market consumption $C_{t}^{m}$, for given search cost $\kappa v_{t}$ and price dispersion $\Delta_{t}$, is linear in $N_{t}$. That is, moving a worker from the home to the market production sector yields a proportional change in the argument of the utility function, $C_{t}$, and volatility in $N_{t}$ does not result in an additional quadratic term in $L_{t}$ once the consumption term is included in the loss function. The quadratic labor market tightness term derives from the wedge between fluctuations in $Y_{t}$ and 
fluctuations in $C_{t}^{m}$, since $Y_{t}-C_{t}^{m}=\kappa v_{t}$. This wedge (and its deviation from the efficient level) is not proportional to $N_{t}$, or $C_{t}^{m}$, since the optimal choice of vacancies depends on labor market tightness, and (11) makes clear that the same level of market tightness can be consistent with different levels of employment. Similar to the standard new Keynesian model, where the impact of price stickiness on the allocation can be disaggregated into inefficient fluctuations in labor and inefficient relative price dispersion, the impact of the search friction can be disaggregated into inefficient fluctuations in labor and inefficient allocation of resources devoted to search.

The weight to place on the $\tilde{\theta}$ gap relative to consumption-gap volatility is equal to $(1-\alpha) \kappa \bar{V} / \bar{C}$. Rewriting this as $(1-\alpha)\left(\bar{C}^{m} / \bar{C}\right)\left(\kappa \bar{V} / \bar{C}^{m}\right)$ shows that as vacancy costs associated with producing market consumption rise or market consumption's share of total consumption rises, the welfare costs of $\theta$-gap fluctuations increases. From the matching function, $1-\alpha$ is the elasticity of the value of a filled job with respect to $\theta$. Thus, if $1-\alpha$ is large, volatility in the $\tilde{\theta}$-gap generates large fluctuations in the value of jobs, and this translates into large and inefficient movements in vacancies.

Given the constant-returns-to-scale matching function, the efficiency condition for job posting depends on labor market tightness rather than on either the level of vacancies or unemployment separately. If the fiscal authority employes a subsidy-tax policy that eliminates the distortion due to imperfect competition in the retail goods market, and if we calibrate the Nash bargaining parameter $b$ so that it is constant and equal to $1-\alpha$, the matching process satisfies the Hosios condition. In this case, unemployment variability in the flexible-price equilibrium is efficient. Hence, optimal policy should, conditional on the other policy objectives, attempt to keep labor market tightness equal to its efficient level by closing the $\tilde{\theta}$ gap.

In a similar model, Thomas (2008) derives a second order approximation to the utility of the representative agent composed of two terms: the first one is quadratic in inflation, and is proportional to the loss from price dispersion, while the second one is made up of squares of a number of endogenous variables', including consumption, employment, and labor market tightness. This second term cannot be written in terms of variables measuring gaps relative to the efficient equilibrium, so it does not provide a way to disaggregate the inefficiency created by the search and nominal rigidity distortions. In contrast, our approximation expresses the loss function in terms of inefficiency gaps that the policymaker would want to minimize.

Search generates inefficient movements in aggregate consumption; therefore it affects the equilibrium movements of the consumption gap by changing the transmission mechanism, but not the weight on the consumption gap in the loss function. However, search also generates an inefficient composition of aggregate consumption, which is why, conditional on consumption, it results in an additional objective in the loss function.

Writing the loss function in terms of gaps provides the weights that the policymaker should attach to each efficiency gap, or to each distortion in the economy. Thomas' (2008) objective function results in a weight for the price dispersion inefficiency, but the weights attached to other variables do not measure any inefficiency.

In any model with a search labor market, the search inefficiency stems from inefficient fluctuations of the surplus share assigned to each party. Our approach does not take a stand on the sources of these fluctuations, and assumes they are exogenous. Other micro-founded policy objective function make stronger assumptions on the source of the inefficiency by modeling explicitly 
deviations of the wage and of the surplus share from the efficient equilibrium. Thomas (2008), for example, assumes staggered wage adjustment for both new and incumbent workers. Clearly, we could replicate any endogenous wage sequence generated by a productivity shock by building an appropriate sequence of $b_{t}$ shocks. The optimal policy would, however, differ under our specifications, since the wage deviations in our model are unexpected by the private sector. Given the ongoing debate on the most appropriate way to describe wage setting, and the ambiguous evidence on wage rigidity for new hires (Haefke et al., 2007), our approach provides a reasonable and useful benchmark.

The comparison between the loss function we obtain and the one in BG becomes clear once we rewrite the loss $(23)$ as follows. Since $\tilde{u}_{t+1}=\rho_{u} \tilde{u}_{t}-\alpha \rho \eta \tilde{\theta}_{t}$ and it can be shown that $\tilde{c}_{t}=$ $\left(\delta_{2} \bar{N} / \eta \bar{C}\right)\left(\beta \tilde{u}_{t+1}-\tilde{u}_{t}\right)$,

$$
L_{t}=\pi_{t}^{2}+\bar{\lambda}_{0}\left(\beta \tilde{u}_{t+1}-\tilde{u}_{t}\right)^{2}+\bar{\lambda}_{1}\left(\tilde{u}_{t+1}-\rho_{u} \tilde{u}_{t}\right)^{2},
$$

where $\bar{\lambda}_{0}=\sigma(\delta / \varepsilon)\left(\delta_{2} \bar{N} / \eta \bar{C}\right)^{2}$ and $\bar{\lambda}_{1}=\lambda_{1}(1 / \alpha \rho \eta)^{2}=(1-\alpha)(\delta / \varepsilon)(\kappa \bar{V} / \bar{C})(1 / \alpha \rho \eta)^{2}$. Setting $\tilde{\theta}_{t+i}=0$ for all $i \geq 0$ will, if the initial unemployment gap is zero, ensure that future unemployment rate gaps also remain equal to zero. keeping $\tilde{u}_{t+i}=0$ for all $i \geq 0$ also ensures that $\tilde{c}_{t+i}=0$. Current marginal cost depends on $\tilde{\theta}_{t}$ and $E_{t} \tilde{\theta}_{t+1}$, so keeping the labor tightness gap equal to zero in current and future periods would also ensure a zero inflation rate. However, if $\tilde{u}_{t} \neq 0$, then the central bank must trade-off efficient labor market tightness against volatility in the unemployment gap. With our baseline calibration, $\lambda_{1} \approx 0$, reflecting in part the fact that vacancy costs are small relative to total output. In fact, if we assume terms of the form $(\kappa \bar{V} / \bar{N}) \hat{x}_{t} \hat{y}_{t}$ are third order, then the loss function for a second-order approximation to welfare would take the form

$$
\pi_{t}^{2}+\lambda_{0} \tilde{c}_{t}^{2}
$$

and involve only inflation and the consumption gap. BG also assume hiring costs are small, leading them to drop cross-product terms with hiring costs, so (25) would represent the loss in our model under assumptions similar to those used by BG. However, when expressing loss in terms of inflation and the unemployment gap as in $(24),(1 / \alpha \rho \eta)^{2}$ is approximately 11 under our baseline calibrations, so even when $\lambda_{1}$ is small, we do not drop this term when we derive optimal policy.

\subsection{Responses under optimal monetary policy}

Optimal monetary policy is obtained by minimizing

$$
\left(\frac{1}{2}\right) E_{t} \sum_{i=0}^{\infty} \beta^{i}\left[\pi_{t}^{2}+\bar{\lambda}_{0}\left(\beta \tilde{u}_{t+1}-\tilde{u}_{t}\right)^{2}+\bar{\lambda}_{1}\left(\tilde{u}_{t+1}-\rho_{u} \tilde{u}_{t}\right)^{2}\right]
$$

subject to the unemployment-based IS and Phillips curves, (18) and (19), which we repeat here after imposing the conditions for an efficient steady state and subtracting the flex-price equilibrium conditions to express the constraints on policy in terms of gaps:

$$
\beta \tilde{u}_{t+1}-\tilde{u}_{t}=\beta E_{t} \tilde{u}_{t+2}-\tilde{u}_{t+1}-\left(\frac{1}{\sigma}\right)\left(\frac{\eta \bar{C}}{\delta_{2} \bar{Y}}\right) \tilde{r}_{t}
$$




$$
\begin{aligned}
\pi_{t}= & \beta E_{t} \pi_{t+1}+\left(\frac{\delta}{\alpha \rho \eta}\right) a_{1}\left[\rho_{u} \beta\left(E_{t} \tilde{u}_{t+2}-\rho_{u} \tilde{u}_{t+1}\right)-\left(\tilde{u}_{t+1}-\rho_{u} \tilde{u}_{t}\right)\right] \\
& +\beta \delta a_{3} \tilde{r}_{t}+\delta B \hat{b}_{t} .
\end{aligned}
$$

The productivity shock does not appear in either the objective function or the constraints of the policy problem. Thus, optimal policy insulates inflation and the unemployment gap from productivity shocks and lets actual unemployment move with the efficient, flexible-price unemployment rate. As in the standard new Keynesian model, the optimal response to a productivity shock requires strict inflation targeting. This result, however, is the consequence of our efficient Nash bargaining wage-setting assumption. For values of $b$ different from $1-\alpha$, a productivity shock presents the policy maker with a trade-off between moving the interest rate so as to stabilize inflation or moving the interest rate to steer firms' incentive to post vacancies towards the efficient level. Ravenna and Walsh (2008b) examine in detail the implications of this trade-off for monetary policy.

Notice that the bargaining shock enters (28) as a cost-push shock since it is associated with inefficient fluctuations in unemployment. In the absence of fluctuations in the bargaining shares, monetary policy designed to ensure efficient vacancy posting so that $\tilde{u}_{t}=0$ for all $t$ also ensures that inflation remains at zero and keeps the unemployment gap (and its change) equal to zero. When bargaining shares fluctuate, stabilizing inflation and stabilizing labor market variables become conflicting objectives. Stochastic shifts in the bargaining share presents the central bank with a trade-off between stabilizing inflation and stabilizing variability in the unemployment gap.

We focus on the optimal timeless perspective form of commitment policy. ${ }^{13}$ Given a unit innovation to the bargaining share shock, the dynamic responses of inflation, the unemployment gap, and $\tilde{\theta}_{t}$ are shown in figure 3 for the case of a serially uncorrelated process for $\hat{b}_{t}$ (i.e., $\rho_{b}=0$ ). Figure 4 shows the impulse responses when $\rho_{b}=0.8$. The rise in labor's share due to the positive shock pushes up costs and leads to a rise in inflation. It also leads to an inefficient drop in vacancies and rise in the unemployment gap. Labor market tightness declines. This is the result of both a decrease in the job finding probability and an increase in the probability of filling a vacancy. The shock to the bargaining share generates a dynamic behavior akin to a cost-push shock in the new Keynesian model, where output is below the efficient level and inflation is positive on impact. In our model, unemployment rises above the efficient level (the unemployment gap is positive), implying output is below the flexible-price equilibrium, while inflation rises on impact. The dynamic process of adjustment in the labor market leads to a gradual return of unemployment to its efficient level.

The top panel of table 2 shows that, under the optimal commitment policy, the welfare costs of the bargaining shock are small. The marginal gain from moving from the outcomes under the optimal policy to the complete elimination of the bargaining shocks is equivalent to a steady-state rise in consumption of $0.022 \%$. We believe the absolute size of the loss should be interpreted the caution. In our model, the marginal value of employment depends on the added consumption that can be obtained by moving workers from to the non-market to the market production sector. The trade-off between working and not working is apparently similar to the one faced by the

\footnotetext{
${ }^{13}$ See Woodford (2003) for a discussion of the distinction between the optimal commitment policy, the optimal policy under the timeless perspective, and the optimal continuation commitment policy; see also Jensen and McCallum (forthcoming).
} 
representative household in a model with Walrasian labor market and an intensive hour margin, where more consumption results in fewer hours of leisure. The absolute utility level, however, is not readily comparable across the two modeling frameworks, since in the Walrasian model utility is usually measured net of the labor effort, rather than as the sum of consumption and leisure hours utility. In our framework, utility is the sum of market and non-market consumption, and, given our parameterization, this specification leads to a high steady state level of utility.

\subsection{The role of the loss function}

The welfare-based loss function involves labor market tightness, the consumption gap, as well as inflation. In this section, we investigate the consequences of policies that are optimal for a mis-specified objective function. In particular, we consider the welfare costs of designing policies to minimize an objective function that corresponds to the quadratic loss functions commonly employed in the literature on optimal monetary policy. We consider two alternatives to the welfare-based loss function.

The first alternative simply drops the $\tilde{\theta}_{t}^{2}$ term from the loss function, yielding a loss function that would more closely parallel policy objectives used in a standard new Keynesian model:

$$
L_{t}^{n k} \equiv \pi_{t}^{2}+\lambda_{0} \tilde{c}_{t}^{2}
$$

In this case, policy aims to stabilize inflation volatility and the volatility of the consumption gap. We employ the welfare-based value of $\lambda_{0}$ since, as noted earlier, this is equal to the same value that would arise in a standard new Keynesian model in which utility depends linearly on hours worked. This loss function ignores the inefficiencies arising from search costs in the labor market.

A second loss function that has been employed in the literature includes inflation and the unemployment rate gap:

$$
L_{t}^{u}(\lambda) \equiv \pi_{t}^{2}+\lambda \tilde{u}_{t}^{2}
$$

Such a loss function has been employed in studies by Orphanides and Williams (2007) and is also employed by Sala, Söderström, and Trigari (2008) in a model with search and matching frictions in the labor market. Because (29) represents an ad-hoc specification of policy objectives, there is no clear way to calibrate the value of $\lambda$, the relative weight placed on unemployment objectives. For our baseline, we set $\lambda$ so that the standard deviation of the unemployment gap under commitment is the same when minimizing either (30) or the welfare-based loss function (23). In this case, $\lambda=0.003$. Sala, Söderström, and Trigari (2008) derive optimal policy for various values of $\lambda$ and find that a value of 0.0521 matches the standard deviation of unemployment in their model. ${ }^{14}$ Therefore, we also report results for $\lambda=0.0521$.

Results when policy is based on minimizing (under commitment) the alternative loss functions (23), (29), and (30) are reported in table 2. The first column of the table reports the percentage increase in the welfare-based loss function given by (26) when policy minimizes one of the alternative loss functions. Minimizing (29), for example, decreases social welfare by 4.42 percent. The second column expresses the loss due to bargaining shocks in terms of steady-state consumption

\footnotetext{
${ }^{14}$ Because they express inflation at an annual rate, the actual value of $\lambda$ they use is $16 \times 0.0521=0.833$. Orphanides and Williams (2007) employ a weight of 0.25 on unemployment in their analysis.
} 
loss. This column shows that under the optimal commitment policy that minimizes the welfare loss, the consumption loss is only 0.022 percent of steady-state consumption.

The responses of inflation, the unemployment gap and labor market tightness to a serially correlated bargaining shock are shown in figure 5. For comparison, the lines marked by circles give the impulse responses under the welfare-based optimal commitment policy and are the same as those shown in figure 4 . The responses are quite similar across the different loss functions with the exception of the unemployment rate gap loss function with the weight based on Sala, Söderström, and Trigari (2008). This loss function allows a much greater response of inflation to the bargaining shock and, correspondingly, allows much less movement in the labor market variables. The policy based on the consumption gap loss given by (29) allows the most labor market volatility and almost completely neutralizes the impact of the bargaining shock on inflation. Both the welfarebased policy and the policy that minimizes (30) with $\lambda=0.003$ produce almost identical impulse responses in reaction to the bargaining shock.

The bottom three panels of table 2 show that minimizing the expected present value of (29) or (30) rather than (23) makes very little difference in terms of the welfare cost, as long as the weight on the unemployment gap is small. Note that for the standard new Keynesian loss function (29), the volatility of inflation is close to zero; a policy of price stability would deliver a welfare loss very close to the optimal policy loss. This result does not imply, however, that including search frictions in the new Keynesian model is irrelevant, since it is well known that the optimal policy in the absence of search frictions calls for deviations from price stability following a cost push shock. Rather, and contrary to the standard new Keynesian model, a policy of price stability performs nearly as well as the optimal commitment policy if cost-push shocks are explained by random deviations of the labor's surplus share from the efficient level and firms face hiring costs.

Conditional on achieving the same volatility of the unemployment gap, minimizing a standard loss function in inflation and the unemployment gap does approximately the same in terms of welfare as minimizing the welfare-based loss function that incorporates both the labor market tightness gap and the change in the unemployment gap. However, when $\lambda$ in (24) is increased from 0.003 to 0.0521 , performance deteriorates significantly. The loss function increases by 269 percent relative to the welfare-based optimal policy, and the welfare costs of bargaining shocks expressed increases from 0.022 percent to 0.080 percent of steady-state consumption); the standard deviation of inflation increases by a factor of almost nine, while the standard deviation of the unemployment gap falls by one third.

\subsection{Discretion versus commitment}

The preceding analysis has focused on optimal policy under commitment. In this section, we briefly compare the response to a bargaining shock when policy is conducted in a discretionary regime. Results are reported in table 3 which parallels the cases considered in table 2 for optimal commitment. Several points are worth noting. First, the welfare cost of bargaining shocks under optimal discretion is about 10.5 percent higher than obtained under the optimal commitment policy (0.024 percent of steady-state consumption versus 0.022 percent under commitment). This cost arises primarily from greater volatility of inflation under discretion. In fact, labor market outcomes are quite similar under either commitment or discretion, as shown in figure 6 which 
compares the impulse responses under the two policies. ${ }^{15}$ The path of inflation differs under commitment and discretion primarily because of the differ paths followed by expected inflation under the alternative policy regimes. This is illustrated in figure 7 which decomposes the path of inflation net of the direct effect of the bargaining shock into the contributions of the labor market variables, expected inflation, and the real interest rate cost channel. Finally, under discretion the policy obtained using the standard new Keynesian model objective function results in an allocation closer to the commitment case, and generates a higher welfare than the optimal policy.

Comparing the results in tables 2 and 3 show that outcomes are fairly similar under either commitment or discretion except when policy minimizes a loss function that includes inflation and the unemployment gap with a large weight on unemployment variability. In this case, loss deteriorates significantly relative to policy based on the correct welfare approximation, rising from 0.024 percent of steady-state consumption to 0.444 percent. Discretion also performed much worse than commitment. Optimal discretion based on (30) with a large weight on unemployment gap fluctuations results in the welfare-based loss function being almost 2000 percent higher than is achieved under optimal commitment. The increase in loss occurs because discretion smooths labor market variables to a much greater degree than is done under commitment, with a corresponding increase in the volatility of inflation. Figure 8 shows that, while the immediate impact of rising unemployment on inflation is larger under discretion than commitment, the labor market returns to steady state much faster under discretion. As a consequence, expected inflation remains higher under discretion.

\subsection{The role of the transmission mechanism}

Above we assumed policy was optimal, conditional on the wrong objective. That tells us how important deviations from the correct objective function are in generating welfare losses relative to the optimal plan (Ramsey allocation), but such an exercise is silent on the implications of the consequences if optimal policy is conditional on the wrong constraints - that is, on the wrong transmission mechanism for policy. In this section, we investigate the performance in our model of targeting rules that are optimal for the standard new Keynesian model. Since a central bank is likely to target the wrong objective if its knowledge of the transmission mechanism is inaccurate, we examine the performance of policy rules that would be optimal conditional on an incorrect objective function and on an incorrect transmission mechanism. This exercise provides insights into whether the central bank generates large losses by ignoring the existence of search frictions and search unemployment.

We consider four alternative policy rules that have been widely employed in standard new Keyensian models: 1) the optimal targeting rule under commitment from a timeless perspective $-\pi_{t}=-(\lambda / \delta)\left(\tilde{c}_{t}-\tilde{c}_{t-1}\right)$ where $\lambda=\left(\sigma+\eta_{N}\right)(\delta / \varepsilon)$ and $\eta_{N}=1$ is the parameterized labor supply elasticity in a model with separable utility in consumption and labor hours; 2$)$ the optimal targeting rule under the time-consistent, discretionary policy $\left.-\pi_{t}=-(\lambda / \delta) \tilde{c}_{t} ; 3\right)$ strict inflation targeting $-\pi_{t}=0$; and 4$)$ a Taylor rule $-i_{t}=(0.5 / 4) \tilde{c}_{t-1}+1.5 \pi_{t}{ }^{16}$ results are reported in table 4 .

\footnotetext{
${ }^{15}$ Note that the impulse responses for commitment are the same as those shown in figure 4 .

${ }^{16}$ The coefficient on $\tilde{c}_{t}$ is divided by four to be consistent with the interest rate and inflation rate which, in the model, are expressed at quarterly rates.
} 
Implementing the optimal commitment targeting rule from the standard new Keynesian model leads to a 26 percent increase in the welfare loss (see the first column of table 4) relative to the commitment policy based on minimizing the welfare-based loss function. Interestingly, performance is better under discretion that commitment, but this simply reflects the fact that when policy employs the wrong model, there is no presumption that commitment will lead to better outcomes than discretion. In fact, strict inflation targeting outperforms both the commitment and time-consistent targeting rules. The final row of table 4 shows that the Taylor rule does very poorly, leading to much more inflation variability than any of the other policies considered ${ }^{17}$. The backward-looking policy rule estimated by Clarida, Gali and Gertler (2000) over the BurnsGreenspan tenure for the years 1979-1997 leads to an even worse result, generating a welfare loss equal to $2.45 \%$ of steady state consumption.

\section{The role of labor market structure}

An important advantage of our model is its ability to characterize the optimal policy according to different assumptions about the characteristics of the labor market. For example, Blanchard and Galí (2008) argue that a separation rate $\rho=0.025$ and steady state employment $N=0.9$ (which imply a job-finding probability $p=0.118$ ) are appropriate for studying the European economy, rather than the values of $\rho=0.1$ and $N=0.95$ (which imply $p=0.655$ ) used for a calibration based on the US. These differences translate into an expected duration of unemployment of 4.3 months under the US calibration and 12 months under the EU calibration. Another dimension along which the US and European labor markets differ is the generosity of unemployment benefits. Nickell (1999) reports an average replacement ratio for EU countries of 0.6 and 0.5 for the U.S. ${ }^{18}$ It is important to note that the differences between our US and EU calibrations is restricted to different values of the labor market parameters. Other parameters, including the frequency of price adjustment, are held constant across the two calibrations.

A convenient way to highlight the differences between the US and EU calibrations is to use (27) to eliminate $E_{t} \tilde{u}_{t+2}$ from (28) yielding ${ }^{19}$

$$
\begin{aligned}
\pi_{t}= & \beta E_{t} \pi_{t+1}+\left(\frac{\delta}{\alpha \rho \eta}\right)\left[a_{2}(1+\beta)-a_{1}-\beta a_{2} \rho_{u}\right] \tilde{u}_{t+1} \\
& +\left(\frac{\delta}{\alpha \rho \eta}\right)\left(a_{1} \rho_{u}-a_{2}\right) \tilde{u}_{t}+\delta\left[\beta a_{3}+\left(\frac{a_{2}}{\sigma \alpha \rho \eta}\right)\right] \tilde{r}_{t}+\delta B \hat{b}_{t} .
\end{aligned}
$$

However, when evaluated at the efficient steady-state, $a_{2}=a_{1} \rho_{u}$, and we obtain

$$
\pi_{t}=\beta E_{t} \pi_{t+1}-a_{1} \delta\left[\frac{\left(1-\beta \rho_{u}\right)\left(1-\rho_{u}\right)}{\alpha \rho \eta}\right] \tilde{u}_{t+1}+\delta\left[\beta a_{3}+\left(\frac{a_{1} \rho_{u}}{\sigma \alpha \rho \eta}\right)\right] \tilde{r}_{t}+\delta B \hat{b}_{t} .
$$

Equation (31) is isomorphic to a new Keynesian Phillips curve with an unemployment rate gap replacing an output gap and with a cost channel present, though this latter channel operates

\footnotetext{
${ }^{17}$ The Taylor rule is written in terms of lagged, rather than current consumption, to ensure determinacy of the equilibrium. Kurozumi and van Zandwedge (2008) show that the conditions for determinacy when policy is expressed as an instrument rule are in fact very different from the case of the standard new Keynesian model.

${ }^{18}$ The duration of unemployment benefits is also shorter in the U.S. than in EU countries, on average.

${ }^{19}$ This is equivalent to evaluating (20) at the parameter values that ensure the steady state is efficient.
} 
through the real rate of interest rather than through the nominal rate as in Ravenna and Walsh $(2006){ }^{20}$

The basic inflation adjustment equation given by (31) for the two calibrations are

$$
\pi_{t}=\beta E_{t} \pi_{t+1}-0.093 \tilde{u}_{t+1}+0.099 \tilde{r}_{t}+0.080 \hat{b}_{t}
$$

for the U.S. values and

$$
\pi_{t}=\beta E_{t} \pi_{t+1}-0.073 \tilde{u}_{t+1}+0.942 \tilde{r}_{t}+0.064 \hat{b}_{t}
$$

for the EU values. Two differences are apparent. First, the interest rate channel on inflation is much larger in the EU calibration. Second, inflation is less sensitive to unemployment under the EU calibration as compared to the US calibration. In large part, this reflects the higher persistence of unemployment under the EU calibration, for which $\rho_{u}=0.796$ versus a value of only 0.310 under the US calibration. As seen in (31), the lower degree of persistence reduces the impact of $\tilde{u}_{t+1}$ on inflation. If $\rho_{u}$ is large, both current and future labor market conditions move together, so the impact of current conditions is offset to some degree by the co-movement of expected future conditions. In more flexible labor markets, $\rho_{u}$ is smaller and current unemployment conditions induce a smaller co-movement in expected future conditions. Thus, the impact on inflation is larger. The smaller value of $\rho$ in the EU calibration also operates to reduce the impact of $\tilde{u}_{t+1}$ on inflation for similar reasons.

The higher value of $\rho_{u}$ under the EU calibration also accounts for the larger impact of the real interest rate on inflation. Changes in the real interest rate affect the present discounted value of future labor market tightness. When employment is more persistent, the expected discounted future labor market conditions have a bigger impact on current inflation, so changes in the rate used to discount the future have a correspondingly larger impact on current inflation.

The greater flexibility of the labor market under the US calibration is reflected in the responses of the efficient unemployment rate to a positive, serially correlated productivity shock. This is shown in figure 9, which plots both the US response (which was also shown in figure 2) as a solid line and the EU response as a dashed line. The peak impact under the US calibration is -0.139 and occurs in the second quarter after the productivity shock. In contrast, the peak effect for the EU calibration is only -0.077 and this occurs five quarters after the shock.

Figure 10 plots the responses to a serially correlated shock to labor's bargaining share for the

${ }^{20}$ To understand why lagged unemployment does not appear in (31), note that conditional on $\tilde{r}_{t}$ and $\tilde{u}_{t+1}$, the IS relationship (27) implies that $\tilde{u}_{t}+\beta \tilde{E}_{t} \tilde{u}_{t+2}$ must be constant. A higher value of $\tilde{u}_{t}$, again conditional on $\tilde{u}_{t+1}$, implies greater labor market tightness $\tilde{\theta}_{t}$, as vacancies must be higher to prevent the higher $\tilde{u}_{t}$ from leading to a rise in $\tilde{u}_{t+1}$. Greater labor market tightness in period $t$ raises real marginal cost at $t$ and would tend to increase inflation. But at the same time, $\beta E_{t} \tilde{u}_{t+2}$ must be lower to maintain $\tilde{u}_{t}+\beta E_{t} \tilde{u}_{t+2}$ constant, consistent with the Euler condition. The fall in $\beta E_{t} \tilde{u}_{t+2}$ implies an increase in expected future labor market tightness, and this acts to lower inflation (see 16). The two effects exactly offset leaving inflation independent of lagged unemployment. Marginal cost depends on $\tilde{\theta}_{t}-\beta \rho_{u} E_{t} \tilde{\theta}_{t+1}$, and

$$
\begin{aligned}
\frac{\partial \tilde{\theta}_{t}}{\partial \tilde{u}_{t}}-\beta \rho_{u} \frac{\partial E_{t} \tilde{\theta}_{t+1}}{\partial E_{t} \tilde{u}_{t+1}} \frac{\partial E_{t} \tilde{u}_{t+1}}{\partial \tilde{u}_{t}} & =\frac{\rho_{u}}{\alpha \rho \eta}-\beta \rho_{u}\left(-\frac{1}{\alpha \rho \eta}\right)\left(-\frac{1}{\beta}\right) \\
& =\frac{\rho_{u}}{\alpha \rho \eta}-\left(\frac{\rho_{u}}{\alpha \rho \eta}\right)=0,
\end{aligned}
$$

where all partial derivatives are conditioned on $\tilde{u}_{t+1}$ and $\tilde{r}_{t}$ being held constant and $\partial E_{t} \tilde{u}_{t+1} / \partial \tilde{u}_{t}=-1 / \beta$ from the IS relationship. 
US and EU calibrations. To allow the two cases to be more easily compared, the middle panel shows the response of the level of the standard unemployment rate, as steady-state levels differ under the two calibrations. ${ }^{21}$ The U.S. calibration leads to more volatile in the inflation rate and the labor market variables. Labor market outcomes are less volatility with the EU calibration, but the major difference is the relatively greater stability of inflation, with optimal policy in the EU calibration producing very stable inflation. The key parameter change that produces this result is the reduction in the rate of exogenous job destruction $\rho$ from 0.1 under the U.S. calibration to 0.025 for the EU calibration. To understand this result, consider the limit as $\rho \rightarrow 0$. With no employment turnover, unemployment is constant, and optimal policy reduces to stabilizing the inflation rate at zero.

Results for alternative loss functions with the EU calibration are given in table 4. Regardless of the objective function, both inflation and the unemployment gap are significantly less volatile when the labor market is less flexible. Comparing the last column of table 4 with the corresponding column of table 2 shows that the relative decline in inflation volatility is greater, however. The costs of bargaining shocks under the optimal welfare-based commitment policy for the EU case is less then one-third the cost with the US calibration ( 0.007 of steady-state consumption versus $0.027)$.

Outcomes when policy minimizes the standard loss function (29) with $\lambda=0.0521$ are shown in figure 11. While inflation is much more volatility in this case under both calibrations (compare scales in figures 10 and 11), unemployment is stabilized to a greater degree with the U.S. calibration. The costs of bargaining shocks under inefficient policy is $0.045 \%$ of steady-state consumption for the EU calibration, compared to only $0.007 \%$ under the welfare-based optimal policy.

\section{Conclusions}

In this paper, we have added to the growing literature incorporating labor market frictions into models with nominal rigidities. We show how a sticky-price new Keynesian model with a labor market characterized by search frictions can be reduced to a simple inflation-unemployment gap model that parallels the standard new Keynesian model. By preserving the assumption of real wage flexibility, our results are directly comparable to models with staggered price adjustment and Walrasian labor markets with flexible wages that have been prominent in monetary policy analysis. Our framework allows for a rich characterization of the labor market in terms of exogenous separation rates, labor bargaining power, matching technology productivity and efficiency, and job posting costs.

We derive a second-order approximation to the welfare of the representative household and show how it depends on inflation and the gap between unemployment and the efficient level of unemployment. We show that labor market tightness affects welfare, and all the cost from search inefficiency can be summarized in a single term in the welfare function. The appropriate objective for the policymaker can be expressed solely in terms of inflation and what we have labeled the

\footnotetext{
${ }^{21}$ We have defined $u_{t}$ to include those not in a match at the end of period $t-1$ and those displaced by the exogenous job destruction process at the start of period $t$. Under the US calibration, the steady-state value of $u$ is 0.145 , while for the EU calibration it is 0.123 . Using $1-N_{t}$ as the definition of unemployment, the US and EU values are 0.05 and 0.10 respectively. the much higher number of searching workers for the US is a result of the higher rate of exogenous job destruction.
} 
unemployment gap. The unemployment gap enters the loss function in two ways. First, loss depends on the gap between our measure of labor market tightness and the efficient level of market tightness, and this gap is proportional to a quasi-difference of the unemployment gap. Second, welfare depends on consumption volatility and this can also be expressed in terms of a quasi-difference of the unemployment gap. The trade-off between stabilizing the terms in the welfare function is the result of random deviations from efficient surplus sharing across firms and workers. Our approach does not take a stand on the sources of these fluctuations, and does not assume any endogenous constraint affecting the wage adjustment, exactly as in the standard new Keynesian model.

Our results show that including search frictions and unemployment in a model with staggered price adjustment preserves some of the monetary policy results common to new Keynesian models (namely, the policy maker's loss can be expressed as a function of inflation and a measure of real activity, and productivity shocks do not generate a trade-off but require movements in the real activity variable). Search frictions in the labor market, beside affecting the goals of the policy maker, change the monetary transmission mechanism by adding a cost channel along with the traditional demand channel. In general, the presence of labor market frictions reduces the difference between responses under optimal commitment and optimal discretion. Ignoring the role of labor market frictions in setting the objectives of policy can lead to large losses. In particular, a policy designed to minimize inflation volatility and unemployment gap volatility can produce a significant reduction in welfare if a moderately large weight in placed on unemployment objectives. If the central bank ignores the impact of labor market frictions in both the objective function and the propagation mechanism of shocks, and implements the optimal targeting rule derived from a standard new Keynesian model, outcomes are inferior to those obtained under strict inflation targeting. In fact, the optimal time consistent targeting rule from the basic new Keynesiam model performs better in the face of labor search frictions than the optimal commitment rule from that model. We also fund that, if the labor market becomes less flexible, and employment dynamics more muted in response to random shocks, optimal policy calls for greater inflation stability. 


\section{References}

[1] Alexopoulos, M., "Unemployment and the business cycle," Journal of Monetary Economics, 51(2), March 2004, 257-298.

[2] Blanchard, O. J. and Jordi Galí, "Real wage rigidity and the new Keynesian model," Feb. 2006.

[3] Blanchard, O. J. and Jordi Galí, "A new Keynesian model with unemployment," March 2008.

[4] Chéron, A. and F. Langot, 1999, "The Phillips and Beveridge curves revisited," Economics Letters, 1999, 69, 371-376.

[5] Clarida, R., Gali, J. and Gertler, M., "Monetary policy rules and macroeconomic stability: evidence and some theory", Quarterly Journal of Economics, 2000, 147-181.

[6] Coibion, O. and Y. Gorodnichenko, "Monetary policy, trend inflation and the Great Moderation: An alternative interpretation," Aug. 2008.

[7] Cooley, T. F. and V. Quadrini, "A neoclassical model of the Phillips curve relation," Journal of Monetary Economics, 44 (2), Oct. 1999 165-193.

[8] Edge, R., "A utility-based welfare criterion in a model with endogenous capital accumulation," Federal Reserve Board, Dec. 2003.

[9] Faia, E., "Optimal monetary policy rules with labor market frictions, Journal of Economic Dynamics and Control, 2007.

[10] Galí, J. and M. Gertler, "Inflation dynamics: A structural econometric analysis," Journal of Monetary Economics, 44 (2), Oct. 1999, 195-222.

[11] Gertler, M., Sala, L. and Antonella Trigari, "An estimated monetary DSGE model with unemployment and staggered nominal wage bargaining", mimeo, IGIER-Bocconi, October 2007.

[12] Gertler, M. and Antonella Trigari, "Unemployment fluctuations with staggered Nash wage bargaining", 2006.

[13] Gordon, R., "Recent developments in the theory of unemployment and inflation", Journal of Monetary Economics 1976, 2: 185-219.

[14] Haefke, C., Sonntag, M., van Rens, T., 2007. Wage rigidity and job creation. Economics Working Papers 1047, Department of Economics and Business, Universitat Pompeu Fabra.

[15] Hall, R. E., "Lost jobs," Brookings Papers on Economic Activity, 1995:1, 221- 256.

[16] Hall, R. E., "Employment fluctuations with equilibrium wage stickiness", American Economic Review 2005, 95: 50-71.

[17] Hosios, Arthur J, "On the efficiency of matching and related models of search and unemployment," Review of Economic Studies, 57(2), 279-298, 1990.

[18] Krause, M. U. and T. A. Lubik, "The (ir)relevance of real wage rigidity in the new Keynesian model with search frictions," Oct. 2008, Journal of Monetary Economics, forthcoming.

[19] Krause, M. U., Lopez-Salido, D. and T. A. Lubik, "Do search frictions matter for inflation dynamics?", Kiel Working Papers 1353, June 2007.

[20] Kurozumi, T. and W. Van Zandwedge, "Labor market search and interest rate policy," Federal Reserve Bank of Kansas City Working Paper 08-03, Oct. 2008. 
[21] Llosa, G. and V. Tuesta, "E-stability of monetary policy when the cost channel matters," mimeo, 2006.

[22] Mortensen, D. T., "Job search, the duration of unemployment, and the Phillips curve," American Economic Review 60(5), Dec. 1970, 847-862.

[23] Mortensen, D. T. and C. A. Pissarides, "Job creation and job destruction in the theory of unemployment," Review of Economic Studies, 61 (3), July 1994, 397-416.

[24] Neiss, K. S. and E. Nelson, "The real interest rate gap as an inflation indicator," Macroeconomic Dynamics, 7, 2003, 239-262.

[25] Orphanides, A. and J. C. Williams, Inflation targeting under imperfect information, in F. Mishkin and K. Schmidt-Hebbel (eds.), Monetary Policy under Inflation Targeting, Central Bank of Chile, 2007.

[26] Ravenna, F. and C. E. Walsh, "Optimal monetary policy with the cost channel," Journal of Monetary Economics 2006, 53, 199-216.

[27] Ravenna, F. and C. E. Walsh, "Vacancies, unemployment, and the Phillips curve," European Economic Review, 52 (2008a), pp. 1494-1521.

[28] Ravenna, F. and C. E. Walsh, "The welfare consequences of monetary policy and the role of the labor market: a tax interpretation," July 2008b.

[29] Sala, L., U. Söderström, and A. Trigari, "Monetary policy under uncertainty in an estimated model with labor market frictions," Journal of Monetary Economics 55, 2008, 983-1006.

[30] Shimer, Robert, "The cyclical behavior of equilibrium unemployment and vacancies", American Economic Review, 95(1), 2005a, 25-51.

[31] Thomas, Carlos, "Search and matching frictions and optimal monetary policy," Journal of Monetary Economics 55, 2008, 936-956

[32] Trigari, A., "Equilibrium unemployment, job flows and inflation dynamics," European Central Bank, Working Paper Series No. 304, Feb. 2004.

[33] Walsh, C. E., "Labor market search and monetary shocks," in Elements of Dynamic Macroeconomic Analysis, S. Altuĝ, J. Chadha, and C. Nolan (eds.), Cambridge: Cambridge University Press, 2003, 451-486.

[34] Walsh, C. E., "Labor market search, sticky prices, and interest rate policies," Review of Economic Dynamics, 8(4), Oct. 2005, 829-849.

[35] Woodford, M., Interest and Prices, Princeotn, NJ: Princeton University Press, 2003. 


\begin{tabular}{|lll|}
\hline \multicolumn{4}{|c|}{ Table 1: Parameter Values } \\
\hline \hline Exogenous separation rate & $\rho$ & 0.1 \\
Vacancy elasticity of matches & $\alpha$ & 0.5 \\
Workers' share of surplus & $b$ & 0.5 \\
Replacement ratio & $\phi$ & 0.5 \\
Vacancy filling rate & $q$ & 0.7 \\
Labor force & $N$ & 0.95 \\
Discount factor & $\beta$ & 0.99 \\
Relative risk aversion & $\sigma$ & 2 \\
Markup & $\mu$ & 1.2 \\
Price adjustment probability & $1-\omega$ & 0.25 \\
\hline
\end{tabular}

\begin{tabular}{|c|c|c|c|c|c|}
\hline \multicolumn{6}{|c|}{ Table 2: Alternative Policy Objectives } \\
\hline \multicolumn{6}{|c|}{ Commitment } \\
\hline Quadratic loss & Velfare-based lc & & & & \\
\hline Relative to Opt. & & & & & \\
\hline Commitment (\%) & Welfare cost* & $\sigma_{\pi}$ & $\sigma_{\tilde{u}}$ & $\sigma_{\tilde{\theta}}$ & $\sigma_{\pi} / \sigma_{\tilde{u}}$ \\
\hline 0 & 0.022 & 0.22 & 0.64 & 10.89 & 0.34 \\
\hline \multicolumn{6}{|c|}{ Std. Loss in $\tilde{c}-$ gap, $\lambda=\lambda_{0}$} \\
\hline 4.42 & $\begin{array}{c}\text { Welfare cost* } \\
0.023\end{array}$ & $\begin{array}{c}\sigma_{\pi} \\
0.02\end{array}$ & $\begin{array}{c}\sigma_{\tilde{u}} \\
0.66\end{array}$ & $\begin{array}{c}\sigma_{\tilde{\theta}} \\
11.37\end{array}$ & $\begin{array}{c}\sigma_{\pi} / \sigma_{\tilde{u}} \\
0.03\end{array}$ \\
\hline \multicolumn{6}{|c|}{ Std. Loss in $\tilde{u}-$ gap, $\lambda=0.003$} \\
\hline 0.41 & $\begin{array}{c}\text { Welfare cost* } \\
0.022\end{array}$ & $\begin{array}{c}\sigma_{\pi} \\
0.18\end{array}$ & $\begin{array}{c}\sigma_{\tilde{u}} \\
0.64\end{array}$ & $\begin{array}{c}\sigma_{\tilde{\theta}} \\
10.99\end{array}$ & $\begin{array}{c}\sigma_{\pi} / \sigma_{\tilde{u}} \\
0.28\end{array}$ \\
\hline \multicolumn{6}{|c|}{ Std. Loss in $\tilde{u}-$ gap, $\lambda=0.052$} \\
\hline 268.54 & $\begin{array}{c}\text { Welfare cost* } \\
0.080\end{array}$ & $\begin{array}{c}\sigma_{\pi} \\
1.81\end{array}$ & $\begin{array}{c}\sigma_{\tilde{u}} \\
0.46\end{array}$ & $\begin{array}{c}\sigma_{\tilde{\theta}} \\
7.69\end{array}$ & $\begin{array}{c}\sigma_{\pi} / \sigma_{\tilde{u}} \\
3.93\end{array}$ \\
\hline
\end{tabular}

* Cost of bargaining shocks under optimal commitment policy as percent of steady-state consumption.

\begin{tabular}{|cccccc|}
\hline \hline \multicolumn{7}{c|}{ Table 3: Alternative Policy Objectives } \\
\hline \multicolumn{7}{c|}{ Discretion } \\
\hline $\begin{array}{c}\text { Quadratic loss } \\
\text { Relative to Opt. } \\
\text { Commit. (\%) } \\
10.48\end{array}$ & $\begin{array}{c}\text { Welfare-based loss } \\
\text { Welfare cost* }\end{array}$ & $\sigma_{\pi}$ & $\sigma_{\tilde{u}}$ & $\sigma_{\tilde{\theta}}$ & $\sigma_{\pi} / \sigma_{\tilde{u}}$ \\
& 0.024 & 0.36 & 0.64 & 10.99 & 0.57 \\
\hline \multicolumn{7}{c}{ Std. Loss in $\tilde{c}-$ gap, $\lambda=\lambda_{0}$} \\
Welfare cost* & $\sigma_{\pi}$ & $\sigma_{\tilde{u}}$ & $\sigma_{\tilde{\theta}}$ & $\sigma_{\pi} / \sigma_{\tilde{u}}$ \\
& 0.023 & 0.02 & 0.66 & 11.37 & 0.03 \\
\hline 12.60 & Std. Loss in $\tilde{u}-$ gap, $\lambda=0.003$ & & \\
& Welfare cost* & $\sigma_{\pi}$ & $\sigma_{\tilde{u}}$ & $\sigma_{\tilde{\theta}}$ & $\sigma_{\pi} / \sigma_{\tilde{u}}$ \\
1928.86 & 0.025 & 0.34 & 0.65 & 11.13 & 0.55 \\
\hline \hline
\end{tabular}

* Cost of bargaining shocks under optimal discretion as percent of steady-state consumption. 


\begin{tabular}{|c|c|c|c|c|c|}
\hline \multicolumn{6}{|c|}{ Baseline NK model optimal commitment policy } \\
\hline $\begin{array}{l}\text { Quadratic loss } \\
\text { Relative to Opt. Commit. (\%) }\end{array}$ & Welfare cost* & $\sigma_{\pi}$ & $\sigma_{\tilde{u}}$ & $\sigma_{\tilde{\theta}}$ & $\sigma_{\pi} / \sigma_{\tilde{u}}$ \\
\hline 26.81 & 0.027 & 0.33 & 0.68 & 15.9 & 0.48 \\
\hline \multicolumn{6}{|c|}{ Baseline NK model optimal discretionary policy } \\
\hline $\begin{array}{l}\text { Quadratic loss } \\
\text { Relative to Opt. Commit. (\%) }\end{array}$ & Welfare cost* & $\sigma_{\pi}$ & $\sigma_{\tilde{u}}$ & $\sigma_{\tilde{\theta}}$ & $\sigma_{\pi} / \sigma_{\tilde{u}}$ \\
\hline 20.55 & 0.026 & 0.21 & 0.69 & 16.2 & 0.30 \\
\hline \multicolumn{6}{|c|}{ Strict Inflation Targeting } \\
\hline $\begin{array}{l}\text { Quadratic loss } \\
\text { Relative to Opt. Commit. (\%) }\end{array}$ & Welfare cost* & $\sigma_{\pi}$ & $\sigma_{\tilde{u}}$ & $\sigma_{\tilde{\theta}}$ & $\sigma_{\pi} / \sigma_{\tilde{u}}$ \\
\hline 5.21 & 0.023 & 0 & 0.66 & 15.6 & 0 \\
\hline \multicolumn{6}{|c|}{ Taylor Rule: $i_{t}=(0.5 / 4) \widetilde{c}_{t-1}+1.5 \pi_{t}$} \\
\hline $\begin{array}{l}\text { Quadratic loss } \\
\text { Relative to Opt. Commit. (\%) }\end{array}$ & Welfare cost* & $\sigma_{\pi}$ & $\sigma_{\tilde{u}}$ & $\sigma_{\tilde{\theta}}$ & $\sigma_{\pi} / \sigma_{\tilde{u}}$ \\
\hline 3405.90 & 0.76 & 1.49 & 0.43 & 10.07 & 3.46 \\
\hline \multicolumn{6}{|c|}{ Estimated policy rule CGG Volker-Greenspan period: $i_{t}=0.71 i_{t-1}+0.29\left[1.72 \widetilde{c}_{t-1}+0.34 \pi_{t-1}\right]$} \\
\hline $\begin{array}{l}\text { Quadratic loss } \\
\text { Relative to Opt. Commit. }(\%)\end{array}$ & Welfare cost* & $\sigma_{\pi}$ & $\sigma_{\tilde{u}}$ & $\sigma_{\tilde{\theta}}$ & $\sigma_{\pi} / \sigma_{\tilde{u}}$ \\
\hline 11420 & 2.45 & 2.72 & 0.38 & 8.90 & 7.16 \\
\hline
\end{tabular}

${ }^{*}$ Cost of bargaining shocks under optimal discretion as percent of steady-state consumption.

\begin{tabular}{|c|c|c|c|c|c|c|}
\hline & Welfare- & oased loss & & & & \\
\hline & Loss as \% of Opt. Policy & Welfare cost* & $\sigma_{\pi}$ & $\sigma_{\tilde{u}}$ & $\sigma_{\tilde{\theta}}$ & $\sigma_{\pi} / \sigma_{\tilde{u}}$ \\
\hline Commitment & 0 & 0.005 & 0.04 & 0.27 & 6.81 & 0.16 \\
\hline Discretion & 0.45 & 0.005 & 0.05 & 0.27 & 6.81 & 0.20 \\
\hline & & Std. I & Sss in & - gap & $=\lambda_{0}$ & \\
\hline & & Welfare cost* & $\sigma_{\pi}$ & $\sigma_{\tilde{u}}$ & $\sigma_{\tilde{\theta}}$ & $\sigma_{\pi} / \sigma_{\tilde{u}}$ \\
\hline Commitment & 0.61 & 0.005 & 0.00 & 0.27 & 6.85 & 0.02 \\
\hline Discretion & 0.48 & 0.005 & 0.00 & 0.27 & 6.85 & 0.02 \\
\hline & & Std. Lo & in $\tilde{u}$ & gap, & $=0.0$ & \\
\hline & & Welfare cost* & $\sigma_{\pi}$ & $\sigma_{\tilde{u}}$ & $\sigma_{\tilde{\theta}}$ & $\sigma_{\pi} / \sigma_{\tilde{u}}$ \\
\hline Commitment & 0.18 & 0.005 & 0.03 & 0.27 & 6.82 & 0.12 \\
\hline Discretion & 1.12 & 0.005 & 0.05 & 0.27 & 6.83 & 0.20 \\
\hline & & Std. Los & in $\tilde{u}$ & gap, & $=0.0$ & \\
\hline & & Welfare cost* & $\sigma_{\pi}$ & $\sigma_{\tilde{u}}$ & $\sigma_{\tilde{\theta}}$ & $\sigma_{\pi} / \sigma_{\tilde{u}}$ \\
\hline Commitment & 94.58 & 0.010 & 0.53 & 0.25 & 6.33 & 2.13 \\
\hline Discretion & 305.50 & 0.022 & 0.90 & 0.25 & 6.44 & 3.65 \\
\hline
\end{tabular}

* Cost of bargaining shocks as percent of steady-state consumption under optimal commitment policy 


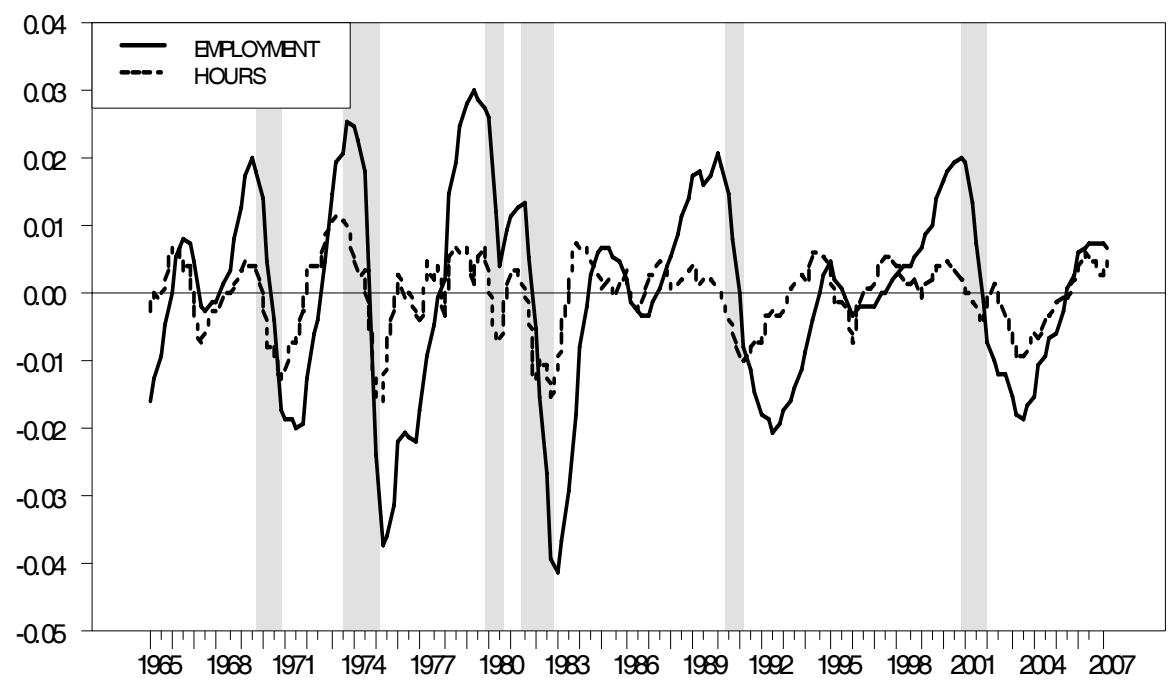

Figure 1: Employment and hours per employee (total private industries, HP detrended, shaded regions denote NBER recession dates)
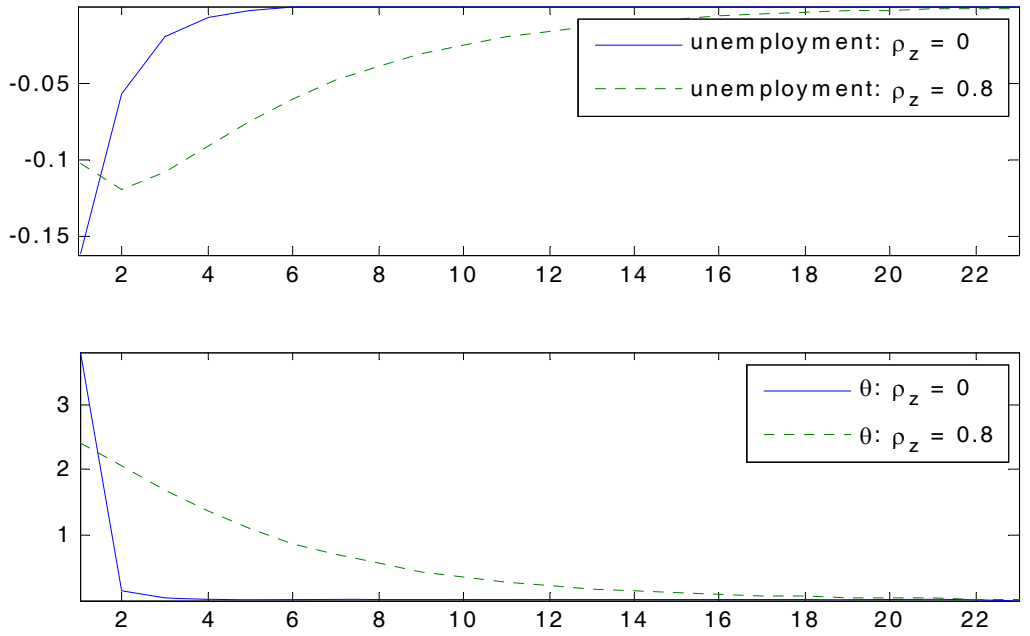

Figure 2: Response of the efficient, flexible-price unemployment rate $\hat{u}_{t}^{e}$ and labor market tightness $\hat{\theta}_{t}^{e}$ to a $1 \%$ positive productivity innovation for different values of $\rho_{z}$. 

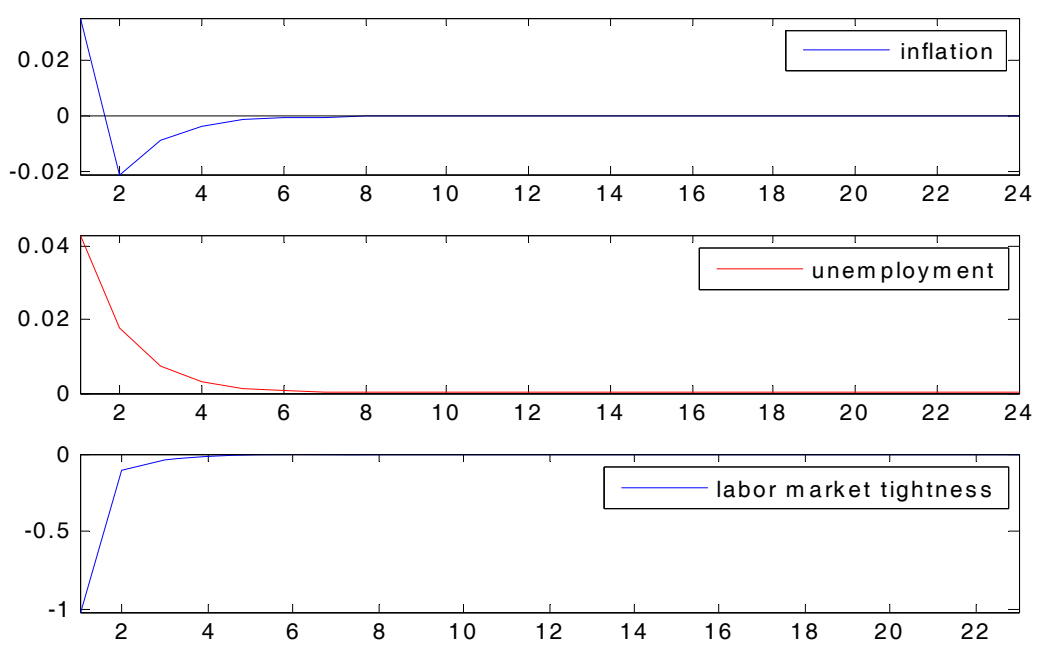

Figure 3: Response to a one unit bargaining shock under optimal commitment: $\rho_{b}=0$
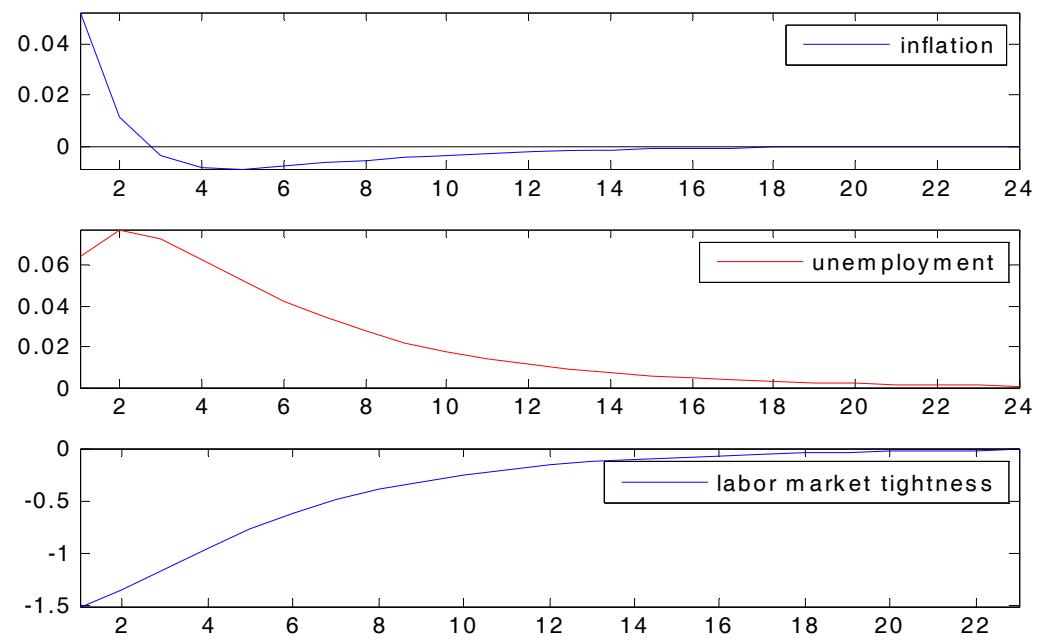

Figure 4: Response to a one unit bargaining shock under optimal commitment: $\rho_{b}=0.8$. 

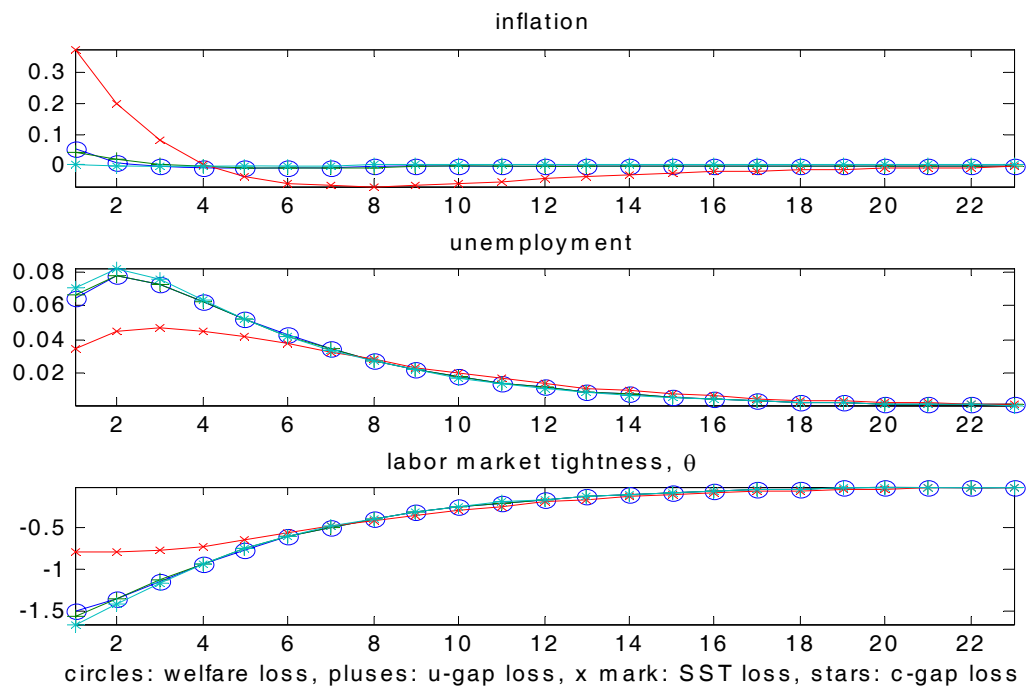

Figure 5: Impulse responses to a one unit bargaining shock under optimal policies minimizing different loss functions
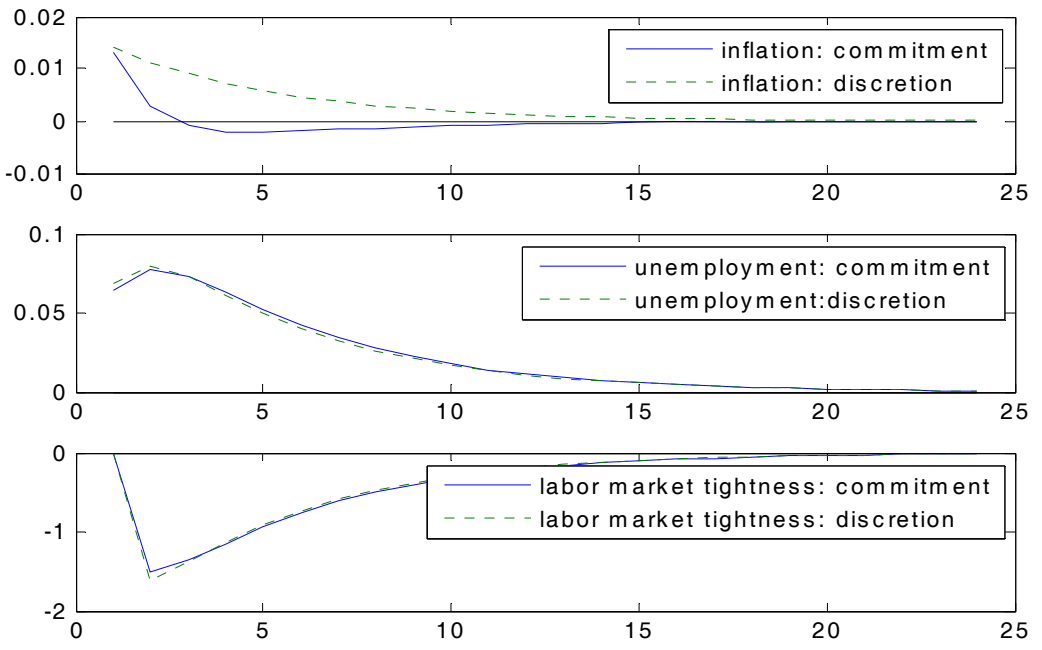

Figure 6: Responses to a bargaining shock under optimal commitment and discretion 

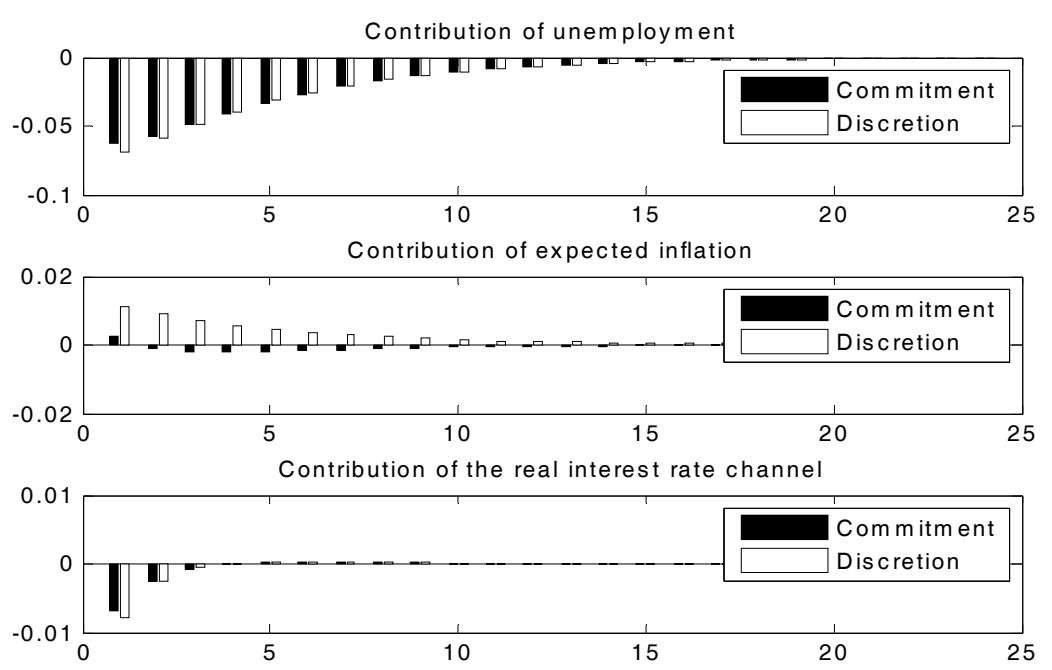

Figure 7: Contribution of labor market, expected inflation, and the real interest rate to the path of inflation net of the direct effect of the bargaining shock when policy is based on the welfare approximation.
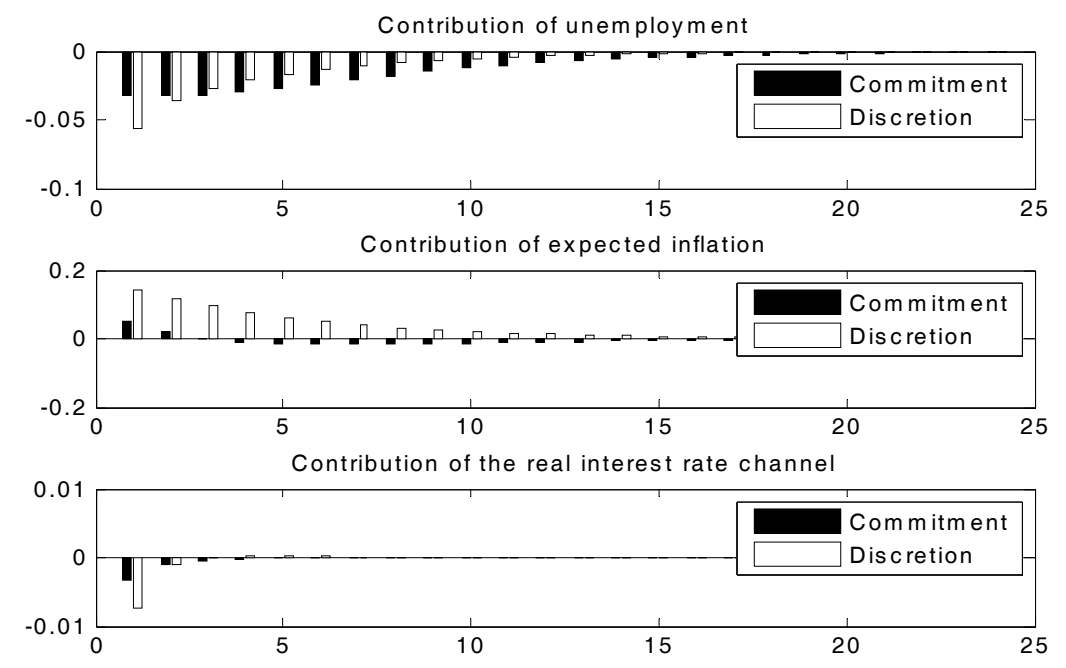

Figure 8: Contribution of labor market, expected inflation, and the real interest rate to the path of inflation net of the direct effect of the bargaining shock when policy is based on the minimizing the exprected present value of $\pi_{t}^{2}+\lambda \tilde{u}_{t}^{2}$ and $\lambda=0.052$. 


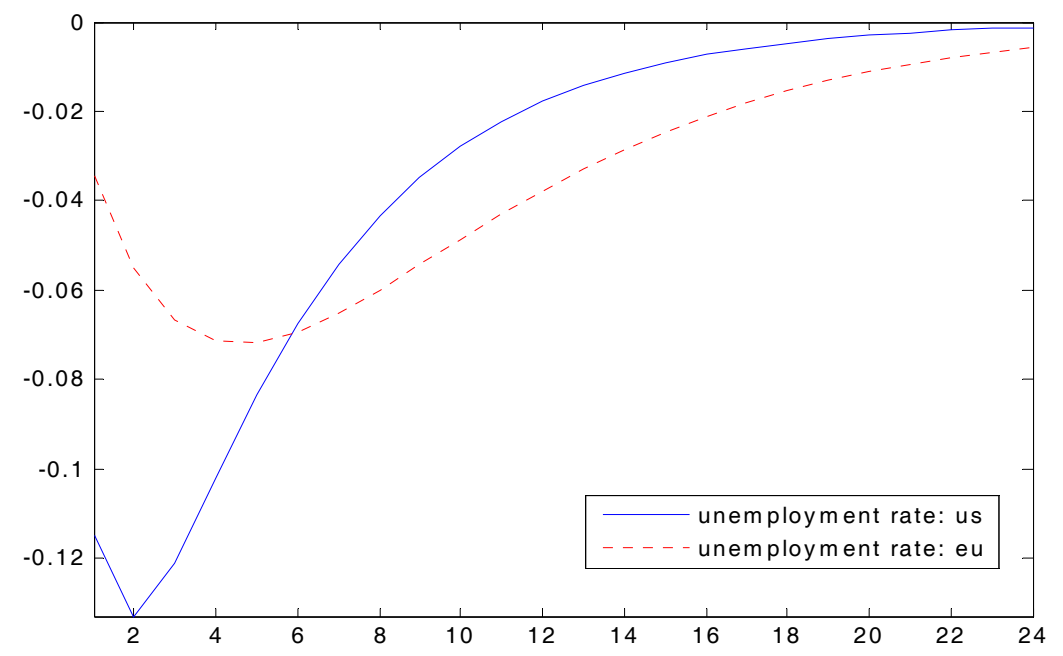

Figure 9: Unemployment rate responses to a serially correlated productivity shock: US and EU calibrations
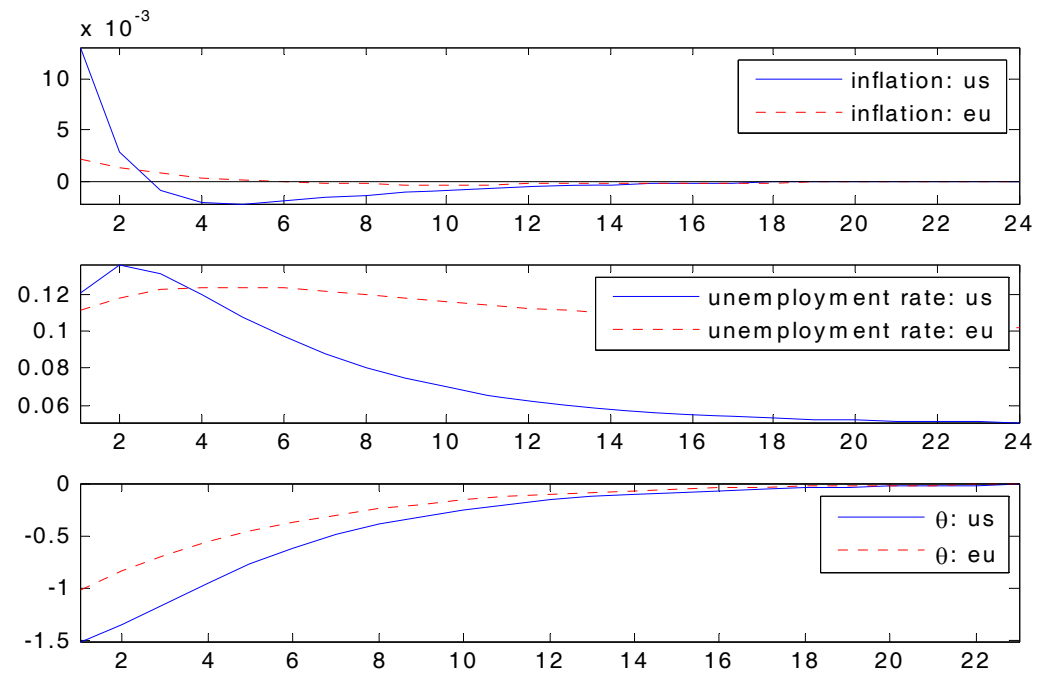

Figure 10: Responses to a unit bargaining shock for U.S. (solid line) and EU (dotted line) calibrations. (Note: middle panel shows the rate of unemployment.) 

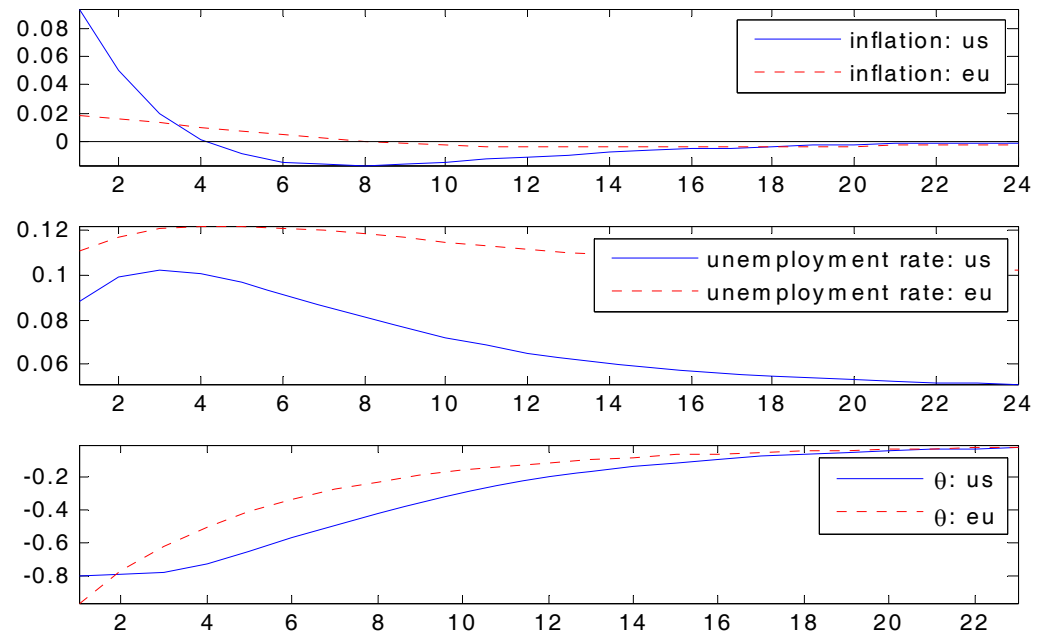

Figure 11: Responses to a unit bargaining shock for U.S. and EU calibrations when policy minimizes the standard loss function (29) with $\lambda=0.0521$. 